\section{LA-6028}

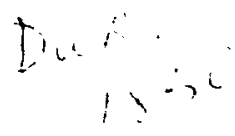

UC-79p

Reporting Date: July 1975 Issued: November 1975

\title{
Experience Related to the Safety of Advanced LMFBR Fuel Elements
}

by

Jerry F. Kerrisk 
Work supported by the U.S. Energy Research and Development Administration's Division of Reactor Research and Development.

Printed in the Unitad Staten of America. Available trom National Technical Information Service

U S Department of Commerce

5285 Port Royal Road

Springfield, VA 22151

Price: Prinled Copy $\$ 100$ Micrutiche \$2.25

This report was prepured an an account of work pponened bs the United statro Goyemment. Neither the United State miniotration. nor any of their employeet, nor any of their contractors. euscontractors, of their emplayees. mukee sny

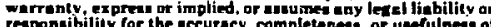
env informetion. opparetur, produrt, or procest diefloned, of repreants that ito use would not isfrinte privalely ownet 


\section{CONTENTS}

ABSTRACT $\ldots \ldots \ldots \ldots \ldots \ldots \ldots \ldots \ldots \ldots \ldots \ldots \ldots \ldots \ldots \ldots$

1. INTRODUCTION $\ldots \ldots \ldots \ldots \ldots \ldots \ldots \ldots \ldots \ldots \ldots \ldots \ldots \ldots \ldots$

2. ADVANCED FUEL ELEMENT DESIGN AND OPERATION $\ldots \ldots \ldots \ldots \ldots \ldots$

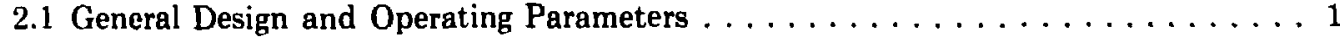

2.2 Unique Features of Advanced Fuel Elements $\ldots \ldots \ldots \ldots \ldots \ldots \ldots \ldots$

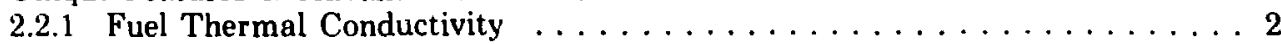

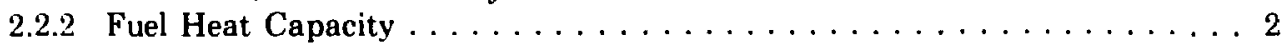

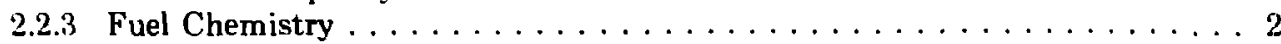

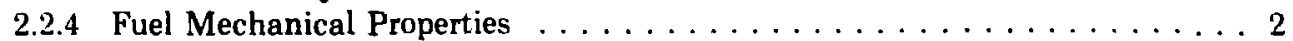

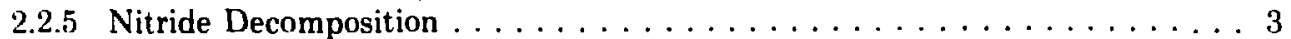

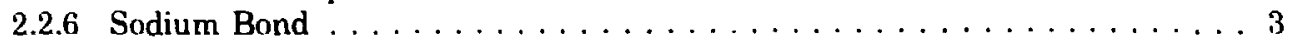

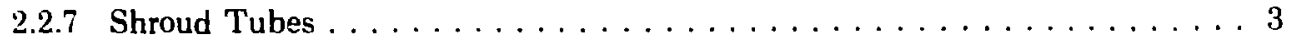

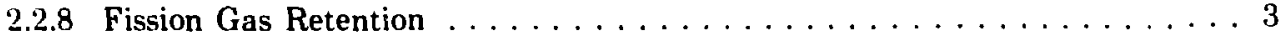

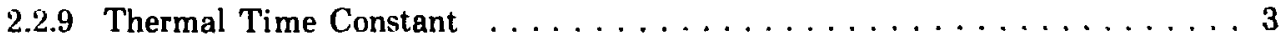

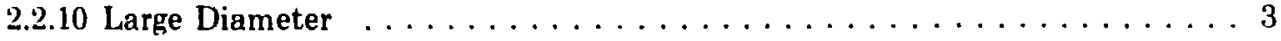

3. AVANCED FUEL ELEMENT SAFETY EXPERIENCE $\ldots \ldots \ldots \ldots \ldots$

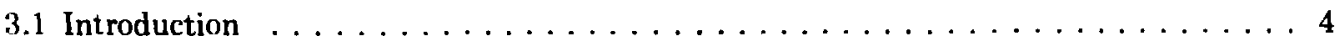

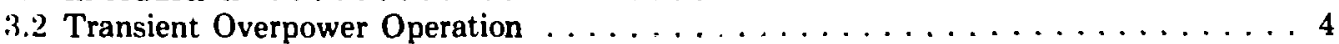

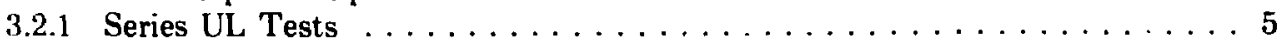

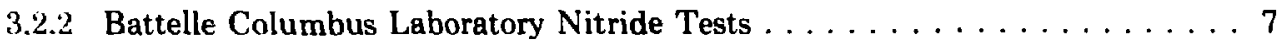

3.2 .3 Atomics International UC Tests . . . . . . . . . . . . . 8

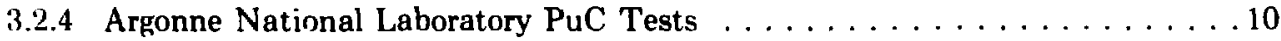

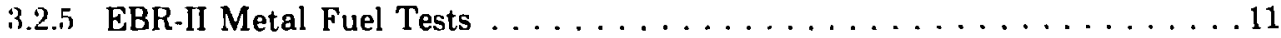

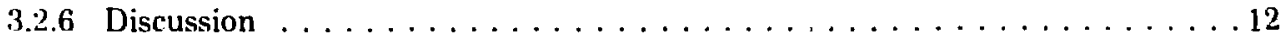

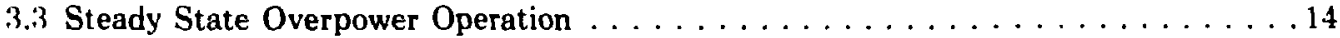

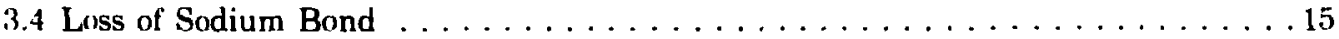

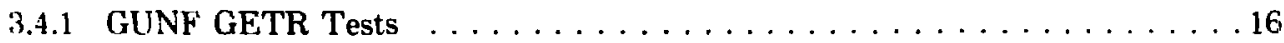

3.4.2 Data From Steady State Irradiation Tests $\ldots \ldots \ldots \ldots \ldots \ldots \ldots$

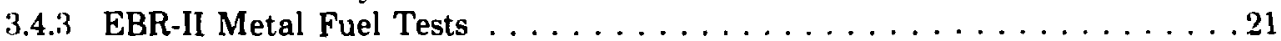

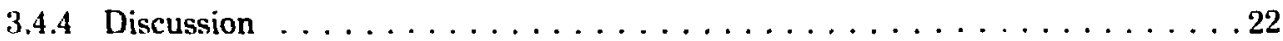

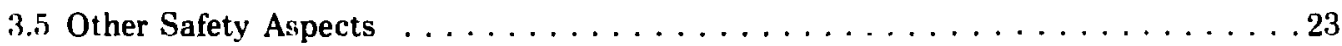

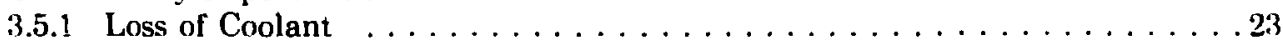

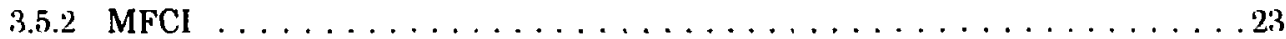

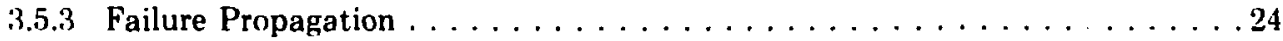

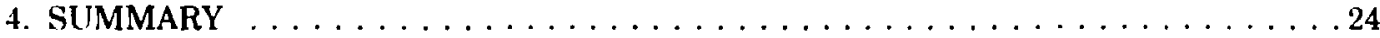

4.1 Transient Overpower Operation of Sodium-Bonded Elements . . . . . . . . . . 24

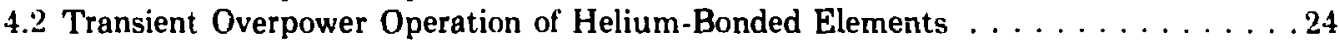

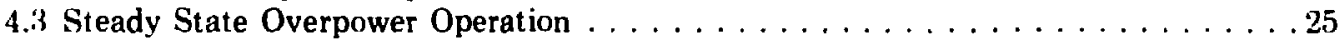

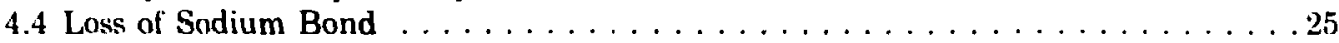

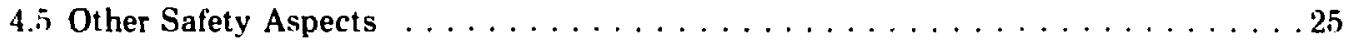

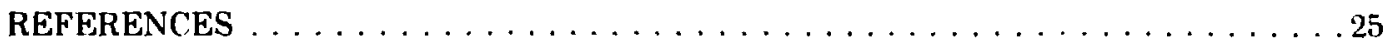

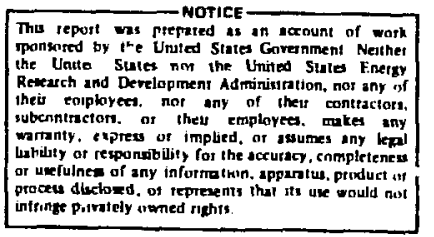




\title{
EXPERIENCE RELATED TO THE SAFETY OF ADVANCED LMFBR FUEL ELEMENTS
}

\author{
by
}

\author{
Jerry F. Kerrisk
}

\begin{abstract}
Experiments and experience relative to the safety of advanced fuel elements for the liquid metal fast breeder reactor are reviewed. The design and operating parameters and some of the unique features of advanced fuel elements are discussed briefly. Trnnsient and steady state overpower operation and loss of sodium bond tests and experience are discussed in detail. Areas where information is lacking are also mentioned.
\end{abstract}

\section{INTRODUCTION}

The U.S. Energy Research and Development Administration is expanding its program for development of advanced breeder fuel systems, to develop fuel and core materials that will permit int roduction of fuel systems having peak burnup capabilities of $150000 \mathrm{MWd} / \mathrm{T}$ and doubling times of $10 \mathrm{yr}$ or less. by the mid-1980's.' Primary emphasis in the advanced fuel program is on uranium-plutonium carbide and uranium-plutonium nitride fuel for the liquid metal fast breeder reactor (LMFBR). Some safety experiments have been performed on advanced $L M F B R$ fuel elements, but a corrdinated safety program for advanced fuels is just beginning. This report reviews experiments and other experience related to advanced LMFBR fuel element safety during irradiation. Although much of this work was not designed as safety experiments. it can provide some insight for future planning. The vast amount of work on safety of uranium-plutonium oxide fuel elements for the LMFBR was not reviewed. For a recent summary of that work, see Ref. 2.

\section{ADVANCED FUEL ELEMENT DESIGN AND OPERATION}

The safety of an advanced fuel element will depend on the nature of the initiating accident and the response of the specific fuel element design to the accident conditions.

\subsection{General Design and Operating Parameters}

A number of fuel element design parameters especially fuel material, fuel-cladding bond, and cladding material, are being investigated in the advanced fuel steady state irradiation program. ${ }^{3-5}$ The fuel materials of interest are $(\mathrm{U}, \mathrm{Pu}) \mathrm{C}$, both as a single-phase monocarbide and with up to about 25 vol $\%(\mathrm{U}, \mathrm{Pu})_{2} \mathrm{C}_{3}$, and $(\mathrm{U}, \mathrm{Pu}) \mathrm{N}$. The $\mathrm{Pu}:(\mathrm{U}+\mathrm{Pu})$ ratio is in the range from 0.15 to 0.25 .

Flements with two types of fuel-cladding bond are heing irradiated. Helium-bonded elements have helium gas as the thermal bond. "The initial diametral gap between the fuel and the cladding is usually $<0.3 \mathrm{~mm}$, so that fuel-cladding mechanical interaction occurs during irradiation, owing to fuel swelling. Fuel centerline temperatures are 1400. $20(1) 0^{\circ} \mathrm{C}$ initially, but they drop during irradiation as the gap closes and hetter thermal contact is obained. Sodium-bonded elements have liquid sudium as the thermal lond. "The initial diametral gap is normaly $0.3-0.8 \mathrm{~mm}$ : this is large enough to allow fuel swelling without fuel cladding contact during the life of the element. The large gap is possible because liquid sodium's high thermal conductivity results in very small temperature drops across 
the gap. Fuel centerline temperatures are normally $<1200^{\circ} \mathrm{C}$.

Sorre sodium-bonded elements also have fuel fragment restraints or shroud tubes, ${ }^{4-6}$ which are perforated, $<0.1-\mathrm{mm}$-wall tubes that fit around the fuel with an approximately $0.005-\mathrm{mm}$ diametral gap. These tubes are designed to keep fragments of cracked fuel pellets from shifting inside the cladding and causing fuel-cladding mechanical interaction during irradiation. Shroud tubes with a high melting point (tantalum) and a low melting point (:316 stainless steel) have been used. Irradiation experiments now being designed use shroud tubes of the same material as the cladding.

Most advanced fuel element irradiations have involved solution-annealed 304 or 316 stainless steel or Incoloy 800 cladding. ${ }^{5}$ Clad tubing thicknesses in helium-bonded elements have been greater than those in sodium-bonded elements to accommodate the expected fuel-cladding mechanical interaction. Present irradiations invoive 20\%, cold-worked 316 stainless steel cladding. In future, high-strength alloys with a higher nickel content than 316 stainless steel will be investigated.

Many other parameters also have been varied in steady state irradiation experiments. ${ }^{5}$ Table I lists some of the important ones and the values investigated. There are no plans at this time to extend values beyond those shown, except for fuel element diameter and fuel column length. Diameters as large as $10 \mathrm{~mm}$ are being considered for irradiation soon. ${ }^{7}$ Fuel column lengths are limited by the $340-\mathrm{mm}$ core height of EBR-II, where most of the irradiations have taken place. Longer fuel columns. more prototypical of commercial application, can be irradiated in the Fast Flux Test Facility (FFTF) when it becomes available.

TABLE I

\section{ADVANCED FUEL ELEMENT DESIGN PARAMETERS}

\begin{tabular}{|c|c|c|}
\hline & Helium-Bonded & Sodium-Bonded \\
\hline Fuel Density (\% Theoret) & 77.99 & 88-99 \\
\hline Fuel Column Length (mm) & $330-350$ & $130-350$ \\
\hline Element o.d. (mm) & $6.8-8$ & $6.5 \cdot 8$ \\
\hline Diamerral Gap (mm) & $<0.4$ & $0.25-1.85$ \\
\hline Cladding Thickness (mm) & $0.22-0.8$ & $0.25 \cdot 0.55$ \\
\hline Linear Power $(\mathrm{kW} / \mathrm{m})$ & $28-96$ & $40-130$ \\
\hline Peak Cladding Temp ( ${ }^{\circ} \mathrm{C}$ ) & $590-650$ & $550-700$ \\
\hline Specific Power (W/g U + Pu) & $100-250$ & $100-300$ \\
\hline
\end{tabular}

\subsection{Unique Features of Advanced Fuel Elements}

The design differences between advanced fin! elements and oxide fuel elements can intluence the causes or outcome of accidents. The impurtant differences and their satt ty implications are discuss ed below.

2.2.1 Fuel Thermal c: mductivity. Buth carbidu. and nitride fuels have high thermal conductivities compared to oxide fuel. At $15(16)^{\circ}(1)^{\circ}, P^{\prime}(1)()$, has at thermal conductivity of about "2 $\mathrm{W} / \mathrm{mK}^{*}$ " whereat both (U,Pu)C and (U,P,I) have conductivities ut about $20 \mathrm{~W} / \mathrm{mK}^{3}{ }^{910}$ This high thermal conctuctivity results in low fuel centerline temperatures in ad. vanced fuel elements of the diameters and yperitic powers now undergning steady state fentitio I riak specific powers of $40\left(0-300 \mathrm{~W} / \mathrm{g}\left(\mathrm{l}^{\prime}+\mathrm{P}_{(1)}\right.\right.$ are $\mathrm{ul}$ timately conceivable v'ith advanced fuets. ${ }^{11} A$ design limit for oxide tuel elements is the linear power that would melt the center of the fivel. Helium-bonded advanced fuel elements new being tested operate with fuel centerline temperaturus $>500^{\circ} \mathrm{C}$ below the fuel solidus temperature; sidium bonded elements operate with fuel centerline temperatures $>1000^{\circ}$ below the luel sulidus temperature. The high fuel thermal inductivity may lead to severer molten fuel-cowlant interintion (MFCI) with advancer' fuels than with ixide's if it leads to faster energy ransfer from the molten fucl to sodium following contact. The fuel's abiliy to ince heat rapidly will also intluence temprature dependent reactivity coefficients (stlth as the Doppler coefficient) during transients. ${ }^{1:}$

2.2.2 Fuel Heat Capacity. The neat rapatity of

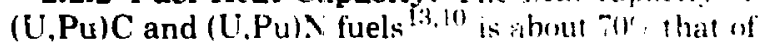
(U.Pu)O.2. 14 This lower heat capacity mean highor fuel temperatures during transiencs, tut it is iffser by the fuels' ability to lose heat faster than oxide fuel can. This difference can also influence MFC' and temperature dependent reactivity crefficients.

2.2.3 Fuel Chemistry. Advanced fucl phemistry differs from that of oxide fuel. and, incleer., the two primary advanced fuel candiclates. $\left(I^{\prime}, \mathrm{P} u\right) \mathrm{C}$ and (U,Pu)N, themselves, differ in chemistry. Must inplications of these differences will show up in the steady state irradiation behavior, hut the various chemical forms of fission products present during accidents and the postaccident situation in which molten fuel might react with other materials must be considered.

2.2.4 Fuel Mechanical Propenties. Little is known about the mechanical properties of advanced 
fuels. ${ }^{15}$ Quantities such as fuel swelling rate, fracture strength, and creep rate are very important for predicting steady state irradiation performance and can be significant in determining failure thresholds during accidents when fuel-cladding mechanical interactions exist. The low operating temperatures of advanced fuels, particularly sodium-bonded elements, produce much lower thermal creep rates than those of oxide fuels.

2.2.5 Nitride Decomposition. At high temperature, (U,Pu)N fuel can decompose into uranium and plutonium metal and nitrogen gas. ${ }^{16-18}$ Decomposition is suppressed by a sufficiently ligh nitrogen overpressure, but it is possible if fuel temperatures exceed $25(x)^{\circ} \mathrm{C}$. If decomposition ocrurs, compatihility hetween decomposed fuel and cladding during continued irradiation, or. in worse circumstancen. MFCI. can be strongly influenced. Vitronen gas formed by decomposition may provide an added fuel dispersal mechanism during severe acridents.

2.2.6 Sodium Bond. The sodium bond in some advanced fiel elements presen:s unique safety problems. These probiems stem mainly from the fact that liquid sudium in the gap between fuel and cladding keeps the gap's thermal conductance very high. but if it is replaced by gas from the plenum above the sudlium bund or by sodium vapor. the thermal comductance is reduced by about an order of magnitude. Thus. severe fuel werheat ing and possible unelting ar nit-ide decompesitiont can occur if ensugin of the sodium hond is voided Conditions such as coids mitially present in the sodium bond or caused by holdup of released fission gas, hond hoil. ing and eject iun due to t ransient overheating, or loss if the bind sudium from the element to the coolant through a cladding defect can cause partial or com. plete bond loss. Also, the possibility of a critical bond bubble size. above which the bond will be com. pletely voided. must be considered. ${ }^{19.20}$ Sodium bond differences in sealed and vented elements tiî vented elements are used/ must also be considered.

2.2.7 Shroud 'Pubes. The shroud rubes t.6 $^{-6}$ some sudium-honded elements can affect their response to transients. More significantly. if a stainless st eel shroud tube melts after sodium bond luss. the disposition of the inolten stainless steel affects the element's continued irradiation behavior.

2.2.8 Fission Gas Rotention. Advanced fuels. buth (I,Pu)C and (I:Pu)N, release less of the fission gas zenerated during irradiation than do oxide fuels. Typical releases range from $\left\langle 1.40{ }^{\circ}\right.$; from advanced fuels with 3.10 at. $\%$ burnups ${ }^{5}$ compared to $50.100^{\circ}$; from oxide fuels with burnups in the same range. ${ }^{21}$ The manner and rate of release of retained fission gas when the fuel is heated only slightly above normal operating temperature (during mild overpower transients) can affect the continued irradiation of the fuel element after the transient. The behavior of retained fission gas during severe overpower transients (when the fuel is nearly or actually melted) can significantly affect the outcome of the accident. High gas retention may provide a built-in fuel dispersal mechanism during severe accidents. Any accident that raises fuel temperatures above the normal operating range can increase fission gas release.

2.2.3 Thermal Time Constant. The thermal time constants of advanced fuel elements are much shorter than those of oxide fuel elements as a direct result of advanced fuels' higher thermal conductivity and of the sodium bond when it is present. Typical time constants are 0.5 and $0.8-1.5 \mathrm{~s}$ for sodium- and helium-bonded advanced fuel elements, respectively, and 2 to $4 \mathrm{~s}$ for oxide elements. The short time constants of advanced fuel elements have implications for their behavior during transients and for coupling of reactivity changes to fuel element temperature changes. ${ }^{12}$ They also indicate that the coolant temperature will follow reactor power and flow variations more rapidly. implying severer thermal stresses in the advanced fuel reactor core structural components.

2.2.10 Large Diameter. Typical oxide fuel element diameters are $<6 \mathrm{~mm}$; present irradiations involve 8 -mm-n.d. (clad) advanced fuel elements, but studies indicate that $10-\mathrm{mm}$ diameters may be optimum. ${ }^{i}$ The safety implications of larger diameter elements are unclear.

\section{ADVANCED FUEL ELEMENT SAFETY EXPERIENCE}

Little satety work has been done specifically for the advanced LMFBR fuel program. Even so, related experiments and experience bear on the safety of advanced fuels.

- Time constants estimated for a step increase in fuel element power generation. They represent the time required for $63^{\circ}$, of the additional power to occur as heat flux to the coolant. 


\subsection{Introduction}

Fuel element accidents can be classified by many methods such as initiating conditions, severity, or wutcome of the accident. Here, they are ordered by initiating conditions as this is generally how safety experiments are plenned. Table II lists a series of possible initiating conditions for accidents, broadly broken into reactor-initiated and element-initiated acciderts. Reastor-initiateri accidents are essential$\mathrm{ly}$ independent of fuel piement design. Elementinitiated accidents are started by some defect in the element or peculiarity in its behavior. and generally depend greatly on its design.

The severity of accidents initiated by these con. ditions can cover a wide range. Mild transients, such as normal operational transients istartup. shutdown. load change, or scram), or off-normal transients terminated by the plant protective system will uccur relatively frequently. ${ }^{22}$ Very severe accidents such as a design basis accident can also be initiated by loss of thow or overpower transients. ${ }^{23}$ The element defects can be minor ones such as small bubbles in a sodium bond with little or no effect, or severer ones such as a complete loss of sodium bond or a flow perturbation from fission gas release. Some conditions such as failure propagation and $\mathrm{MFCl}$ depend on prior failure ot elements.

Although there are many potential initiating conditions for accidents. the ensuing sequences of events are often similar. Certain mechanisms or phenomena will be important in many different ac. cident sequences. Table III lists a series of phenomena which may be important during various stages of accidents. Because of the nature of most of the experimental safety work applicable to advanced fuel elements. the emphasis of this review is on ele. ment failure phenomena.

\subsection{Transient Overpower Operation}

Transient overpower operation of a fuel element senerally results from accidentai reactivity insertion. Postulated transients range from slow. mild ones that are terminated by the plant protective sistem to rapid. high-power ones that disrupt the core. The outcome depends greatly on the transient's severity. Mild transients may result in little or no
TABLE 11

\section{INITIATING CONDITIONS FOR REACTOR ACCIDENTS}

Reactor Initiated

\section{Transient or Sready State Overpower}

Transient Loss of Coolant

Slow-Pump Coastdown

Rapid--Subassembly Blockage or Pipe Ruprure

Gas Bubbles in the Coolant

Element Initiated

Steady State Overpower

Entire Element or Subassembly

Individual Fuei Pellets

Loss of Coolant

Fission Gas Release from an Adjacent Element

Coolant Flow Channel Blockage

Flow Restriction from Element Swelling or Bowing

Loss of Sodium Bond

Partial..Gas Bubbles in the Bond

Complete--Loss Through a Cladding Failure

\author{
MFCl \\ Failure Propagation \\ Element to Element \\ Subassembly to Subassembiy
}

Other Element Defects

change in the fuel element and thus allow continued steady state irradiation. As the transient severity increases, many possible problems arise, such as sodium bond boiling and ejection. increased fission gas release, fuel melting. cladding melting. molten fuel-coolant interaction, and movement of fuel, clad. ding. andi coolant after failure. 
TABBLE III

\section{ACCIDENT SEQUENCE PHENOMENA}

Element Failure Prenomena

Element Response to Operational Transients or Those Terminated by the Plant Protective SystemFailure Probability

Failure Mechanism

Failure Threshold-Significant Parameters

Coherence of Failures

Release of Gas

Rate of Release

Mechanical and Thermal Effects of Release

Reicase of Molten Fuel

Flow Blockage

Molten Fuel-Coolant Interaction

Behavior of Failed Elements During Continued Irradiation

Coolant Phenomena

Location and Timing of Boiling Initiation

Lucal Blockage

Crossflow

Local Boiling

Expulsion and Reentry

\section{Scvert Accident Phenomena}

Fuel Movement

Fission Product Release and Transport

Reactions of Molten Fucl with Reactor Components

Postaccident Heat Remova!

3.2.1 Series UL Tests. The Series UL tests were a juint effort of Los Alamos Scientific Laboratory (I.ASL, and Gulf United Nuclear Fuels Corporation (GINF) to determine how irrudiation affected the failure thresholds of helium- and sodium-bonded
(U,Pu)C fuel elements ${ }^{24,25}$ Table IV describes the elements tested. They are similar to advanced LMFBR fuel elements now under steady state irradiation, except that the peak linear power of the two irradiated ones (UL-3 and 4) during their steady state irradiation was only about half the present 80 . to $85-\mathrm{kW} / \mathrm{m}$ range of interest. Also the fuel density of the helium-bonded elements is higher than that now considered viable for high burnup performance. ${ }^{3}$ The tests were performed in the TREAT reactor. Each test involved a single element in a static cap. sule. No thermal neutron filter was used. Instrumentation consisted of thermocouples outside the element cladding at the top, axial midplane, and bottom of the fuel column. The thermocouples had ungrounded junctions and thus relatively slow response times.

Table V lists some of the Series. UL test results. The power transient shape for each test was nominally the same; a computer-controlied flattop transient with a rapid power increase, a constant power hold for about $1.4 \mathrm{~s}$, and a rapid drop. Owing to the lack of a thermal neutron filter and the relatively high fuel enrichment, therr. was a severe radial power variation in the fuel. The calculated surface: centerline power generation ratio was approximately $\dot{b}$. Besides being atypical of a fast reactor. this flux depression also complicates temperature calculations in the fuel element during the transient.

The Series UL tests are still being evaluated, so this discussion should be considered preliminary. Test UL-1 was designed to melt the fuel center. Calculations indicate that the fuel just reached the solidus temperature. The only examination as yet has been radiography of the element in its inner cap. sule. The transient caused some fuel pellet cracking. but no other significant differences have been observed. It is assumed that this element did not fail.

Test UL-2 was designed to produce boiling and ejection of the bond sodium, followed by fuel melting. The thermocouple output gave no indication of bond boiling or ejection. Although the ungrounded junction thermocouples outside the cladding responded relatively slowly, the reduced heat transfer associated with bond ejection should have been observable. The calculated peak bond temperature was $1040^{\circ} \mathrm{C}$, about $100^{\circ} \mathrm{C}$ above the boiling temperature of the sodium bond in the element. It is thought that bond ejection did not occur. and that if any bond boiling occurred it was confined to a very short time during the peak temperatures in the bond region, essentially at the end of the transient. As bond ejection did not occur, the pegk fuel 


\section{SERIES UL TEST ELEMENTS}

\begin{tabular}{|c|c|c|c|c|}
\hline & UL-1 & UL-2 & UL-3 & UL-4 \\
\hline Fuel Element No. ${ }^{\mathrm{a}}$ & $263(138 A)$ & $264(146 \mathrm{~A})$ & $265(138)$ & $266(146)$ \\
\hline Fuel Marerialb & \multicolumn{4}{|c|}{$-{ }_{-} 90 \mathrm{vol} \%\left(\mathrm{U}_{0.85} \mathrm{Pu}_{0.15}\right) \mathrm{C}+10 \mathrm{vol} \%\left(\mathrm{U}_{0.85} \mathrm{Pu}_{0.15}\right)_{2} \mathrm{C}_{3}$} \\
\hline Fuel o.d. (mm) & 6.25 & 6.09 & 6.25 & 6.09 \\
\hline Fuel Density (\% Theor) & $98-99$ & 98.99 & $98-99$ & 98.99 \\
\hline Gmear Density ( $\%$ Theor ) & 90 & 77 & 90 & 77 \\
\hline Bond Material & $\mathrm{He}$ & $\mathrm{Na}$ & $\mathrm{He}$ & $\mathrm{Na}$ \\
\hline Diametral Bond Thickness (mm) & 0.25 & 0.77 & 0.25 & 0.77 \\
\hline Cladding Materials & $316 \mathrm{SS}$ & 304 SS & $316 \mathrm{SS}$ & 304 sS \\
\hline Cladding Thickness (mm) & 0.56 & 0.38 & 0.56 & 0.38 \\
\hline Cladding o.d. (mm) & 7.62 & 7.62 & 7.62 & 7.62 \\
\hline Fuel Column Length (mm) & $349 \pm 3$ & $349 \pm 3$ & $349 \pm 3$ & $349 \pm 3$ \\
\hline Burnup (at. $\%$ ) & $\mathbf{0}$ & 0 & $3.56^{\mathrm{d}}$ & $3.62^{\mathrm{d}}$ \\
\hline
\end{tabular}

TABLE V

SERIES UL TRANSIENT

OVERPOWER TEST RESULTS

\begin{tabular}{|c|c|c|c|c|}
\hline & UL-1 $\mathbf{1}^{\mathrm{a}}$ & UL-2 & UL-3 & UL-4 \\
\hline Reactor Energy (MWs) & 159 & 161.5 & 157 & 156 \\
\hline Peak Reactor Power (MW) & 106 & 104 & $10 \mathrm{i} .5$ & 101 \\
\hline Fission Energy ( $\mathrm{J} / \mathrm{g}$ fuel) & 912 & 967 & 866 & 891 \\
\hline Peak Fission Power $(\mathrm{kW} / \mathrm{m})$ & 239 & 233 & 221 & 217 \\
\hline Initial Element Temp. $\left({ }^{\circ} \mathrm{C}\right)$ & 260 & 260 & 260 & 260 \\
\hline Peak Fuel Temp. $\left({ }^{\circ} \mathrm{C}\right)$ & 2300 & 1500 & $1760-2200$ & 1400 \\
\hline Peak Cladding Temp. $\left({ }^{\circ} \mathrm{C}\right)$ & 850 & 1000 & $800-900$ & 950 \\
\hline
\end{tabular}

\footnotetext{
${ }^{a}$ This test was preceded by two calibration transients involving the same capsule.
} 
temperatures must have been much lower than anticipated. The peak fuel temperature in Table $V$ was chleulated assuming that the sodium bond remained liquid during the tratsient. The only examination as yet is radiography of the element in its inner capsule. No significant changes were seen, not even fuel craching. It is assumed that this element did not fail

Tesit IL.3 was to duplicate UI.- I with an irradiated colement. 'Total energy deposition and peak linear power were $5-7 "$, below the $1: L$ - 1 values. The calculated peak fuel temperature in Table $V$ is uncertain owing to the uncertainty in the fuel"ladding heat transfer coefficient after 3.56 at."; burnup. This elernent failed hecause of the transient. A perturbation in the thermocouple temperatures starting at abeut 4.5 s probahly resulted from gas blanketing of the hermocouples for a short time after vlement failure and releas: of fission gas. At t.is. the transient was essentially complete. Fxamination showed fission gas outside the element. Three axial cracks were visible in the cladding. all in the lower half of the fuel column. The largest. near the bottom. was fol $\mathrm{mm}$ long. No fuel was lost through the cladding cracks. Profilometry hefore and after the transient showed similar cladding ovalities, the postiransient ones being sur:ewwat larger. The fuel column length increased (1.6' : owing to the transient, mostly from the upward expansion of the tup pellet. Flux peaking at the ends of the fuel colurnn and the unrest rained condition of the (op) caused higher temperatures and higher fission gas release in the top pellet. No signs of high fission gas release were seen in radingraphs of the bot tom pellet which was restrained by the fuel column above it. The cladding cracks were mostly interuranular. Furt her postirradiation data or analyses are not yet available.

Test UL-4 was to duplicate LiL.2 with an irradiated element. The total energy deposition and peak linear puwer were $T-8$ ', below the UL-2 values. so the peak fuel and cladding temperatures were also slightly lower. This element did not fail. The fuel pellets were already cracked as a result of the EBR-II irradiation. Radiography showed additional crack. ing and pellet movement as a result of the transient. but no other significant changes were observed in the fuel region. The fuel column length increased $3^{r}$; relatively uniformly over its entire length. No holddown spring was used in the sodium-bonded elements. A sodium plug about $75 \mathrm{~mm}$ long and cont aining about $80^{\circ} ;$ of the sodium in the element was found in the element plenum after the transient. The bottom of the plug was about $65 \mathrm{~mm}$ above the top of the upper insulator pellet. Fission gas samples were taken both above and belov the plug. Above, the gas was $4.6^{\prime}$; fission gas (krypton and xenon) and $95.4^{\prime} ;$ helium: below, it was $98.6^{\circ} ;$ fission gas and $1.3^{\prime}$; helium. It appears that retained fission gas released during the transient dispiaced the bond sodium up into the plenum. This must have occurred eithe: late in the transient or after the transient as the thermocouple temperatures showed no perturbations that would indicate cutoff of heat transfer from the fue!. The plenum temperature where the sodium plug was found was over $200^{\circ} \mathrm{C}$ at the start of the transient and remained above the melting point of sodium $\left(97.8^{\circ} \mathrm{C}\right)$ for over $2 \mathrm{~h}$ after the transient. Therefore, the sodium did not freeze on being dis. placed into the plenum. but stayed in place as a molten plug for at least $2 \mathrm{~h}$. Calculations indicate that surface tension forces were adequate to stabilize the molten sodium in the plenım. A proliminary conclusion of the examination is chat all the features ohserved in the postirradiation metallography could be accounted for by steady state irradiation alone. Further data and analyses are not yet atnilable.

\subsubsection{Bsttelle Columbus Laboratory Nitrid} Tests. Battelle Columbus Laboratory (BCL) has rur overpower tests on (U.Pu)N fuel elements ${ }^{2 S-31}$ to investigate nitride fuel behavior under overpower conditions that would boil the sodium boud. ${ }^{32}$ Table $V I$ describes the elements. They are like current LMFBR advanced fuel elements except that the fuel column is only $1 / 5$ as long as normal EBR-II elements. The tests were run in TREAT using a static capsule which contained two longitudinally stacked elements. The elements had different heat sink sleeves. so the power generation in the lower element was $-85^{\prime}$ '; of that in the upper. No thermal neutror. filter was used. Temperatures were measured at six locations on the upper element and three on the lower by thermocouples attached to the cladding.

The first test was in June 1971, but analysis of the reactor power and energy lata, temperature data. and neutron radiographs indiceted that the desired conditions were not achieved. The sane capsule and elements were subjected to a second tiansient in March 1972. Tabie VII lists some of the results. The transients were relatively long, computer-controlled. flat top transients. The calculated surface: certerline power generation ratio in the fuel was approximately 4. This is less severe ihan those in the Series UL tests because the nitride elements contained natural uranium. The thermocouple temperatures from the first transient gave no indication of sodium bond boiling. This was confirmed by temperature calculations. Neutron radiography was the only examination after the first transient. Some pellet 


\section{TABLE. VI}

\section{BCL NITRIDE TEST ELEMENT DESIGN}

Fucl Material ${ }^{2}$
Fuel o.d (mm)
Fuel Density (\% Theor)
Smear Density ( $\%$ Theor)
Bond Material
Diametral Bond Thickness (mm)
Cladding Material
Cladding Thickness (mm)
Cladding o.d. (mm)
Fuel Column Length (mm)
Burnup (at.\%)

$\left(\mathrm{U}_{0.8} \mathrm{Pu}_{0.2}\right) \mathrm{N}$
5.72
$93-95$
$75-77$
Sodium
0.64
$304 \mathrm{SS}$
0.51
7.37
63
0

\footnotetext{
${ }^{3}$ Natural uranium. Fuel was pressed and sintered pellets.

b'The plenum over the sodium hond was pressurized to $3.5 \mathrm{alm}$ at $25^{\circ} \mathrm{C}$ during fabrication.
}

movement was ubserved in the top element. During the second transient, sodium bond boiling was estimated to have started at $12-13 \mathrm{~s}$ in the upper element. and to have continued throughout the transient. The calculated fuel surface temperature at that time was $1: 30-170^{\circ} \mathrm{C}$ above the local $1090^{\circ} \mathrm{C}$ sudium bond boiling temperature. The thermocouple response to the sodium bond boiling was not as great as anticipated.

There was only minimal postirradiation examination of these elements. ${ }^{32}$ Neutron radiographs indicated no significant damage, although the fuel

TABLE VII

\section{BCL NITRIDE ELEMENT TRANSIENT OVERPOWER TEST RESULTS}

\begin{tabular}{|c|c|}
\hline & $\begin{array}{l}\text { Junc } 1971 \\
\text { Transient }\end{array}$ \\
\hline Reactor Energy (MWs) & 1180 \\
\hline Peak Reactor Power (MW) & 65 \\
\hline Transient Duration (s) & -18 \\
\hline Encrgy Deposition (J/g fuel) $)^{-}$ & 8600 \\
\hline l'eak Power $(\mathrm{kW} / \mathrm{m})$ & 164 \\
\hline Initial Element Temp. $\left({ }^{\circ} \mathrm{C}\right)$ & 120 \\
\hline Peak Fuel Temp. $\left({ }^{\circ} \mathrm{C}\right)$ & $1+40$ \\
\hline Peak Cladding Temp. ("C) & 1025 \\
\hline Sodium Bond Boiling & None \\
\hline
\end{tabular}

Murch 1972

Transient

1450

98

$-15$

10600

247

120

1815

1210

At $12 \cdot 13 \mathrm{~s}$

into transient

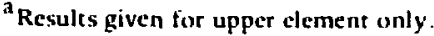

cilculated from other data presented.
}

pellet displacements suggested rladding deformatiou. The elements were removed from the capsule, and visual examination revealed no cladding damage. Cladding diameters were within 0.0):3 mm ot the initial diameter. The upper element was cut open, and the pellets were examined sisually. They were cracked but not melted. No metallography was done.

3.2.3 Atomics International UC Tests. Atomics International (A1) ran a series of transient overpower tests on sodium-bonded ITC elements ${ }^{33.3 .37}$ to examine the entire spectrum of events that accur during nuclear transient heating of fuel elements. Phase I covered sudium-bonded IT elements up to the onset of fucl melting. ${ }^{3,34}$ Phase Il examined similar elements during last and slow transients that melted the fuel. ${ }^{34}$ it Plase III, to study unbonded (gas-bonded) uranium carbide and oxide elements during fuel-melting transients, was never carried out . 36

The fuel flements for these tests were similar to the Hallam Nuclear Power Facility, Core II fuel. Table VIII describes the two elements apiece tested in Phases I and II. They differ significantly from present advanced LMFBR tuel elements (see Table IV). In particular, the diameier is much larger; the fuel is cast, as upposed to pressed and sintered pellets, and contains no plutonium; the sodium bond is thicker; and the fuel column is short.

The rests were run in TRFAT using simgle elements in static capsules. $N o$ thermal neutron filter was used. Phase I instrumentation included a cent ral fuel thermocouple, two thermocouples in the sodium bond, a coolant thermocouple in the galp hetween the cladding and heat sink, and a pressure transducer that measured the pressure in the fuel element plenum above the sodium bond. The thermocouples were all at the axial mioplane of the fuel. The Phase II tests used a central and a midradius fuel thermocouple and two element sodium bond thermocouples, all at the axial midplane of the fuel: an element sodium bond thermocouple at the bottom of the luel: coolant thermocnuples at the top. midplane, and bottom of the fuel; and a pressure transducer like that for Phase I. The fuel thermocouples were sodium-bonded to the fuel to give a short response time.

The transients were unshaped ones, initiated and controlled by TREAT reactivity. Table IX lists the test parameters. including an estimate of the power pulse width at half-maximum. Each test transient was preceded by at least one calibration transient The Phase I and Phase II Capsule 1 tests used similar transients. forming a series of increasing total energy and peak power, and decreasing pulse 
TABLE VIII

\section{AI UC TEST ELEMENTS}

Fuel Material
Uranium Enrichment (\%)
Fuel o.d. (mm)
Fuel Density (\% Theor.)
Smear Density (\% Theor.)
Eond Marerial ${ }^{\text {b }}$
Diametral Bond Thickness (mm)
Cladding Material
Cladding Thickness (mm)
Cladding o.d. (mm)
Fuel Column Length (mm)
Burnup (at.\%)

pecially in the Phase II calibration transients, indicated that the actual ratio was less than calculated.

The Phase I Capsule 1 test involved a peak fuel temperature just abcve $1500^{\circ} \mathrm{C}$. This took the fuel through the range where any free uranium (the fuel was hypostoichiometric) would melt, but not to the UC melting point $2500-2560^{\circ} \mathrm{C}$. A thermal arrest in the fuel centerline temperature at about $1100^{\circ} \mathrm{C}$ corresponded to the $1133^{\circ} \mathrm{C}$ uranium melting point. The bond thermocouples gave no indication of sodium bond boiling. Posttransient examination showed the cladding above the fuel slug to be collapsed. The collapse apparently occurred during the pretransient sodium melting when coolant sodium (outside the cladding) melted at the bottom before melting at the top. Posttransient metallography showed some fuel cracks, but they were attributed to the sectioning. There was no apparent change in the fuel microstricture.

The Phase I Capsule 2 test involved a peak fuel

${ }^{\mathrm{a}}$ Hypostoichiometric UC ( $4.6 \mathrm{wt} \% \mathrm{C}$ ) arc-cast into a single slug.

${ }^{b}$ The plenum pressure over the boud was $1 \mathrm{~atm}\left(25^{\circ} \mathrm{C}\right)$.

width at half-maximum. The Phase II Capsule 2 test used a long, low-power transient. Neutronic calculations indicated a fuel surface:centerline power generation ratio of about 2 to 2.5 . Comparison of caiculated and measured fuel temperatures, estemperature of $2315^{\circ} \mathrm{C}$. A thermal arrest was evident in the fuel temperature gt about $1100^{\circ} \mathrm{C}$ during this transient also. Anomalous behavior of the fuel centerline thermocouple near its maximum may' have been caused by free uranium. The sodium bond boiled at approximately $980^{\circ} \mathrm{C}$, which corresponds to the boiling point at the 2.2-atm pretransient plenum pressure. The bond thermocouple

TABLE IX

AI UC TRANSIENT OVERPOWER TEST RESULTS

\begin{tabular}{|c|c|c|c|c|}
\hline & \multicolumn{2}{|c|}{ Phase 1} & \multicolumn{2}{|c|}{ Phase II } \\
\hline & Capsule $\mathbf{1}^{\mathbf{a}}$ & Capsule $\mathbf{2}^{\mathbf{b}}$ & Capsule $\mathbf{1}^{\mathbf{b}}$ & Capsule $\mathbf{2}^{\mathbf{b}}$ \\
\hline Reactor Energy (MWs) & 181 & 293 & 525 & 598 \\
\hline Transient Width at $1 / 2$ Power (s) & $\sim 1$ & $\sim 1 / 2$ & $\sim 1 / 4$ & $\sim 10$ \\
\hline Maximum Reactor Powct (MW) & 260 & 615 & 1560 & 55.8 \\
\hline Energy Deposition (Jig fuel) & 425 & 690 & 1350 & 1535 \\
\hline Peak Power $(\mathrm{kW} / \mathrm{m})$ & 3145 & 7440 & 19500 & 705 \\
\hline Initiai Element Temp. $\left({ }^{\circ} \mathrm{C}\right)$ & 370 & 370 & 370 & 370 \\
\hline Peak Fuel Temp. $\left({ }^{\circ} \mathrm{C}\right)$ & 1515 & 2315 & 3600 & 2500 \\
\hline Peák Cladding Temp. $\left({ }^{\circ} \mathrm{C}\right)$ & $\sim 750$ & $\sim 950$ & $\sim 950^{d}$ & $\sim 950$ \\
\hline Sodium Bond Boiling & No & Yes & Yes & Yes \\
\hline Peak Pressure (atm) $)^{c}$ & $\sim 3.5$ & $\sim 3.5$ & $\sim 17$ & $\sim 3.5$ \\
\hline
\end{tabular}


temperatures were interpreted to indicate bond boiling, bond voiding, and quenching as cold sodium from above the fuel reentered the bond area. Examination of the internal cladding surface above the fuel showed that sodium had splashed up into this region. The lack of high plenum pressures from sodium bond boiling was explained by the cooler sodiuni above the fuel having quenched any sodium vapor formed. The fuel had many microcracks. This type of cracking was not seen in the Phase I Capsule 1 fuel. It was attributed to thermal stresses resulting from the transient. The UC microstructure did not change because of the transient (there was no indication of melting), but much less free uranium was visible, because of solution of free uranium in the UC during the transient.

The Phase II Capsule 1 test involved a peak fuel temperature of $3600^{\circ} \mathrm{C}$, well above the UC melting point. The sequence of events deduced from the thermocouple temperatures was (1) sodium bond boiling and voiding, (2) central fuel melting, (3) surface fuel melting and fuel-cladding contact, (4) cladding melting, (5) mixing of the molten fuel and cladding with the stagnant coolant sodium, and (6) -. dispersal of the fuel, cladding, and sodium mixture by rapid vaporization of the coolant sodium. The sodium bond boiled and voided early in the transient $(1 / 2 \mathrm{~s})$ at about $980^{\circ} \mathrm{C}$. At this point, only about half the total energy had been deposited. Peak fuel temperatures occurred at the completion of the energy deposition ( $1 \mathrm{~s})$. The molten fuel and cladding and the coolant sodium did not interact until about $2 \mathrm{~s}$ into the transient, one full second after completion of the energy deposition. This interaction was signaled by coolant ti ormocouple temperature oscillations and pressure pulses with a maximum of about 17 atm. An x-radiograph and visual examination of the sectioned capsule showed considerable fuel dispersal, especially up into the top of the capsule. No sodium was found in the lower part of the capsule; rather, it was frozen on the surfaces of the heat sink and upper sections of the capsule, along with part of the fuel and cladding. Metallography of the fuel and cladding residue showed significant interaction and a dendritic structure formed during resolidification. Possibly, part of the fuel did not melt completely.

The Phase II Capsule 2 test gave a peak fuel temperature of $2500^{\circ} \mathrm{C}$, just at the UC melting point. This was a long, low-power transient compared to the previous three. System temperatures rose slowly. Sodium bond boiling started at the fuel axial midplane at about $12 \mathrm{~s}$ (when $35 \%$ of the energy deposition was complete). The sodium bond thermocouple at the bottom of the fuel seemed to level off about $200^{\circ} \mathrm{C}$ below the midplane bond thermocouple until $16 \mathrm{~s}$, when it rapidly rose to the same temperature as at the midplane. It is postulated that the boiling in the upper half of the sodium bond expanded into the lower half between 12 and $16 \mathrm{~s}$. Sodium bond thermocouples continued to indicate relatively constant $900-950^{\circ} \mathrm{C}$ temperatures until $40 \mathrm{~s}$, well after the end of the transient. At 12-16 s (when bond boiling started), the coolant thermocouple at the axial midplane dropped about $100^{\circ} \mathrm{C}$ indicating reduced heat transfer to the coolant. This was attributed to the bond boiling. Also, an increase in the rate of fuel temperature rise at about $14 \mathrm{~s}$ could be ascribed to bond boiling. The element pressure increased about $1.4 \mathrm{~atm}$ between 12 and 16s. A significant drop in the rate of fuel temperature increase at $16 \mathrm{~s}\left(2250^{\circ} \mathrm{C}\right)$ was taken to indicate melting of the central fuel region. Examination indicated no gross fuel melting, although the fuel and bond thermocouples were fused to the fuel. There was no apparent change in the fuel microstructure. This fact seemed to be at variance with the thermocouple data, but it was explained by the similarity of the cooling cycles during the transient and the initial casting process.

\subsubsection{Argonne National Laboratory PuC Tests.} Argonne National Laboratory (ANL) ran three transient overpower tests on helium-bonded elements containing vibratorily compacted $\mathrm{PuC}$ fuel ${ }^{38-40}$ to determine the behavior of unirradiated fuel during abnormal reactor operation. The elements (Table $X$ ) were similar to those undergoing iteady state irradiation in various reactors, ${ }^{39}$ but different from present LMFBR design. The fuel, a powder, was vibratorily compacted into the clad tubing. Helium filled the free volume between fuel particles, but did not act as a thermal bond in the same sense as it does for fuel pellets. The elements were smaller in diameter than present advanced fuel designs, and the cladding on C-40 and C-41 was atypical.

The tests were performed in TREAT in static capsules with an inert gas surrounding the elements. No thermal neutron filter was used. Each element had three thermocouples attached to the cladding. Table $\mathrm{X}$ summarizes the results. Both $\mathrm{C}-40$ and $\mathrm{C}-41$ were intact, but the 304 stainless steel cladding of F-9 failed because of extensive melting. The failure was not violent. Metallography of F-9 showed a molten phase that had interacted with the cladding. The PuC fuel was hypostoichiometric $(3.5 \mathrm{wt} \% \mathrm{C})$, so it was postulated that it contained molten plutonium above $900^{\circ} \mathrm{C}$, and that a low-melting plutonium-iron eutectic formed when the molten plutonium contacted the stainless steel cladding. The cladding 
TABLE X

\section{ANL PuC TEST ELEMENTS AND RESULTS}

\begin{tabular}{|c|c|c|c|}
\hline Fuel Element No. & $\mathrm{C}-40$ & C. 41 & F-9 \\
\hline Fuel Material ${ }^{\mathrm{a}}$ & $-\mathbf{H}$ & jichiometric $\mathrm{Pu}$ & \\
\hline Fuel Density (\% Theor) & $\sim 95$ & $\sim 95$ & $\sim 95$ \\
\hline Smear Density (\% Theor) & $\sim 80$ & $\sim 80$ & $\sim 80$ \\
\hline Bond Material & Helium & Helium & Helium \\
\hline Cladding Material & $\mathrm{Nb}-1 \mathrm{wt} \% \mathrm{Zr}$ & $\mathrm{Nb}-1 \mathrm{wt} \% \mathrm{Zr}$ & 304 SS \\
\hline Cladding Thickness (mm) & 0.23 & 0.23 & 0.23 \\
\hline Cladding o.d. (mm) & 4.45 & 4.45 & 4.45 \\
\hline Fuel Column Length (mm) & 60 & 60 & 60 \\
\hline TREAT Reactor Energy (MWs) & 13.2 & 21.2 & 29.2 \\
\hline Maximum Cladding Temp $\left({ }^{\circ} \mathrm{C}\right)$ & 900 & 1210 & 1435 \\
\hline Postrransient Condition & Unfailed & Unfailed & Failed \\
\hline
\end{tabular}

temperatures during the transient indicated that failure occurred approximately 2.7 a after molten plutonium touched the cladding. Claddin: temperatures were $987-1377^{\circ} \mathrm{C}$ at failure.

3.2.5 EBR-II Metal Fuel Tests. There have been many transient overpower tests of EBR-II driver fuel elements $^{41-44}$ to study failure mode and threshold, effect of prior irradiation on failure thresholds, postfailure movement of fuel and coolant, and sodium expilsion and reentry. These tests are not reviewed in the sane detail as the ceramic fuel tests, because the metal fuel elements differ so from advanced fuel elements that few behavior similarities can be expected. However, the behavior of the EBR-Il fuel element sodium bond may provide useful information.

Table XI describes the EBR-II fuel element. ${ }^{45}$ The metal alloy fuel melts at $1000-1100^{\circ} \mathrm{C}$, and this fact influences much of the overpower behavior. The element diameter and sodium bond thickness are less than those of current advanced fuel elements. A further difference is the gas plenum volume. Most advanced fuel elements have a plenum volume: fuel volume ratio of about 1 . The EBR-II element ratio is about an order of magnitude smaller. This difference could influence sodium bond behavior during bond overheating.

The overpower tests of EBR-II metal fuel elements have been run in TREAT under a large variety of conditions. Capsules with inert gas, stagnant sodium, and flowing sodium around single or multiple fuel elements have been used. Thermal neutron filters have not been used, but axial power profiles have been shaped by using absorbers. Instrumenta-

tion has included pressure transducers, flow meters, and thermocouples in the fuel, at the fuel-cladding interface, on the cladding, and in the coolant.

Two failure mechanisms for these elements have been identified. The first involves formation of a low-melting iron-uranium eutectic at the fuelcladding interface. Failure was correlated with the interface temperatures reached during overpower transients in tests with inert gas and stagnant sodium surrounding the elements. Tests with flowing sodium seemed to allow interface temperatures above the approximately $1000^{\circ} \mathrm{C}$ limit observed in the nonflowing systems without failure. The second failure mechanism, observed mainly in the flowing

TABLE XI

EBR-II METAL FUEL ELEMENT DESIGN

Fuel Material

Fuel o.d. (mm)

Fuel Density (\% Theor)

Smear Density (\% Theor)

Bond Material

Diametral Bond Thickness (mm)

Cladding Material

Cladding Thickness (mm)

Cladding o.d. (mm)

Fuel Column Length (mm)

${ }^{a}$ Uranium enrichment varied from $0.7 \%$ (natural) to $9 \%$ in various tests.

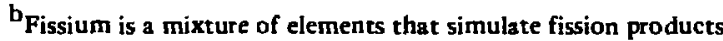
in the amount expected in EBR-Il fuel after it reaches its equilibrium composition through pyrometallurgical refining. 
sodium tests, was large internal element pressure attributed to vaporization of the bond sodium. Upward fuel movement during transients (detected by the neutron hodoscope) was also attributed to sodiur: bond vaporization. This movement can relieve some of the pressure in the fuel region. It seemed effective in tests of single elements (surrounded by six dummy elements that did not contain fuel) in flowing sodium, but in two tests of seven-element clusters, failure occurred despite up. ward fuel movement.

After element failure in the flowing sodium systems, fuel movement varied with environment. In two single-element tests, fuel froze on the test section wall and there was no appreciable secondary fuel movement. In two tests of seven-element clusters, fuel was transported out of the test section into other parts of the loop. The difference was ascribed to the relatively cold surroundings in the single-element tests. Fuel expelled from the central element of a cluster or from the inside of the six outer elements in multiple-element tests had no cold wall on which to solidify.

3.2.6 Discussion. Although a number of transient overpower experiments relate to advanced LMFBR fuel elements, there is little directly applicable information. The important question of what the failure thresholds in advanced fuel elements are can be answered only very preliminarily. However, some insight can be gained about failure mechanisms and important parameters in transient overpower tests.

Most of the experimental work relates to sodiumbonded elements. The sodium-bonded elements in the Series UL and BCL Nitride tests did not fail. One can infer from the lack of cladding deformation that three of the four AI UC test elements (Phase I Capsules 1 and 2, and Phase II Capsule 2) did not fail either. The only failed sodium-bonded elements are the AI UC Phase II Capsule 1 element and a number of metal elements. The failure mechanism postulated for the failed AI UC element (Sec. 3.2.3) may be applicable to advanced LMFBR fuel elements, but caution should be exercised in making this extrapolation in light of the different failure mechanisms observed for EBR-II metal fuel elements in static capsule tests and in tests with flowing coolant (Sec. 3.2.5). The failed AI UC element was subjected to such gross overpower that it hardly represents a failure threshold: it was more like a severe accident. The moderate pressures measured indicate that severe MFCI did not occur. This is one of the few experiments that relate to advanced fuel MFCI (Sec. 3.5.2). Of the two failure mechanisms postulated for EBR-II metal fuel elements, fuel-cladding eutectic formation does not apply. The high internal pressures generated by sodium bond vaporization in the EBR-Il elements may be related to their small plenum volume, and may not occur in advanced fuel elements whose plenum: fuel volume ratio is near 1 . This follows from the low pressures observed in the AI UC tests in which the plenum: fuel volume ratio $u$ is also approximately 1. A large plenum may provide a cooler region where vaporized sodium can recondense before creating significant pressure buildup.

Three other significant tests are the AI UC Phase I Capsule 2 and Phase II Capsule 2 tests and BCL Nitride tests (second transient) in which the sodium bond boiled but the elements remained intact. The AI UC Phase II Capsule 2 test in which the bond boiled for over $20 \mathrm{~s}$ without cladding failure requires particular discussion. Attempts to model sodium bond boiling have assumed bond ejection and gas blanketing of the fuel. ${ }^{46}$ Possibly, some type of refluxing action continues to supply liquid sodium to the bond region during boiling. If so, complete bond ejection and dryout of the bond region may require a long time or very high fuel temperatures. Such things as bond gap thickness (which in advanced fuel elements is only $1 / 2$ to $1 / 6$ of that in the AI UC elements) may determine how bond boiling progresses. A modeling effort would be a very useful complement to the tests.

These experiments give different answers to the question of when sodium bond boiling starts. The AI UC tests indicate that boiling occurred when the bond sodium reached its boiling point. In the BCL Nitride test, the bond was about $100^{\circ} \mathrm{C}$ above the sodium boiling point when boiling started. In test UL-2, the peak bond temperature was about $100{ }^{\circ} \mathrm{C}$ above the sodium boiling point but there was no in dication of boiling. The Series UL and BCL Nitride tests indicate superheat in the bond sodium. whereas the AI UC tests indicate essentially none. This disagreement could be due to material differences, element differences (the AI UC test elements had much thicker sodium bonds), or errors in temperature calculations. This question is certainly important enough to be pursued in future testing.

Another mechanism that can lead to consequences like those of sodium bond boiling is bond displacement by released fission gas, as in test UL-4. Bond displacement can occur during relatively mild overpower transients that merely raise the fuel temperature above its normal operating range. Further overpower tests on irradiated sodiumbonded elements in a flowing sodium loop may be needed to determine the stability of a molten sodium plug in a fuel element plenum when flow vibrations 
are present. A fuel holddown spring may also affect the stability of sodium displaced into the plenum.

The significant parameters in sodium-bonded fuel element failure are not apparent from these data. Total energy deposition is not a useful parameter, as energy deposition rates and capsule designs varied tremendously throughout the tests. In the BCL Nitride tests, $>10000 \mathrm{~J} / \mathrm{g}$ of fuel were deposited in the second transient without element failure, whereas gross failure occurred in the AI UC Phase II Capsule 1 test with only $1350 \mathrm{~J} / \mathrm{g}$ of fuel deposited. This difference was due to the BCL capsule which had a very large heat sink thermally honded to the fuel element; the heat sink absorbed most of the energy generated in the fuel. Perhaps the most meaningful failure threshold parameter during transient overpower is peak fuel temperature. Table XII lists the overpower transient tests on sodium-bonded ceramic fuels in order of decreasing calculated peak fuel temperature. For unirradiated elements, the failure threshold appears to be in the fuel-melting region. A more specific parameter may be the amount of fuel that melts. ${ }^{47}$ The one test of an irradiated element exhibited a further phenomenon, release of retained fission gas. The failure threshold of irradiated elements will undoubtedly be a func- tion of burnup, probably lowering with increasing burnup. The behavior of nitride fuel heated above $2500^{\circ} \mathrm{C}$ may also affect failure thresholds of nitride fuel elements.

The two Series UL tests of helium-bonded elements provide some information about failure thresholds. The UL-3 element failed near the end of the transient, thus providing a reasonahle failure threshold estimate for irradiated helium-bonded elements of that design. Unfortunately, the peak fuel temperature is in doubt owing to uncertainty about the fuel-cladding heat transfer coefficeint. The axially cracked cladding implies that internal pressure on the cladding probably caused failure. Differential thermal expansion of the fuel and cladding, released fission gas, or fuel swelling may have caused the internal pressure. During steady state irradiation of helium-bonded elements, fuel swelling leads to mechanical interaction between fuel and cladding. ${ }^{5}$ If mechanical contact was established with the steady state temperature gradient in the element, the overpower transient would produce higher fuel temperatures relative to the cladding, greater fuel thermal expansion, and thus greater mechanical interaction. Fission gas released during the transient may also have contributed to the internal pressure

TABLE XII

TRANSIENT OVERPOWER TESTS ON SODIUM-BONDED CERAMIC FUELS

(ordered by peak fuel temperature)

\begin{tabular}{|c|c|c|}
\hline Test & $\begin{array}{c}\text { Peak Fuei } \\
\text { Temp } \\
\left({ }^{\circ} \mathrm{C}\right)\end{array}$ & Remarks \\
\hline AI UC Phase II Capsule 1 & 3600 & Gross destruction of element. \\
\hline AI UC Phase II Capsule 2 & 2500 & $\begin{array}{l}\text { Extensive sodium bond boiling, } \\
\text { probable fuel melting, element unfailed. }\end{array}$ \\
\hline AI UC Phase I Capsule 2 & 2315 & $\begin{array}{l}\text { Sodium bond boiling, possible fuel } \\
\text { melting, element unfailed. }\end{array}$ \\
\hline BCL Nitride, 2nd Transient & 1815 & Sodium bond boiling, element unfailed. \\
\hline AI UC Phase I Capsule 1 & 1515 & Element unfailed. \\
\hline UL-2 & 1500 & Element unfailed. \\
\hline UL-4 & 1400 & $\begin{array}{l}\text { Bond displacemr:nt by fission gas } \\
\text { release, element unfailed. }\end{array}$ \\
\hline
\end{tabular}


on the cladding, especially if it was trapped in the fuel region. Fission gas flow around and through the fuel to the plenum in a helium-bonded element may be slow enough to trap in the fuel region most of the gas released during a rapid transient. ${ }^{48}$ The fact that the UL-3 element contained $98-99 \%$ theoretical density fuel (not now considered useable for heliumbonded elements) ${ }^{3}$ and that it was irradiated at a low, 40- to $45-\mathrm{kW} / \mathrm{m}$ linear power may indicate that its failure threshold differs from that of present element designs. In particular, use of low, $80-85 \%$ theoretical density fuel may raise the failure threshold. The results of the UL-1 unirradiated helium-bonded element test substantiate the generally accepted belief that the failure threshold of unirradiated elements is higher than that of irradiated elements of the same design. ${ }^{47}$

The ANL PuC helium-bonded element tests are difficult to compare with the UL tests because of differences in fuel composition and element and capsule design. There is no evidence that the uraniumplutonium carbide fuel (monocarbide or monocarbide plus some sesquicarbide) now used in advanced fuel elements will release molten metal at high temperature. Uranium-plutonium nitride decomposes into nitrogen gas and metal, but only at very high tem peratures $\left(>2500^{\circ} \mathrm{C}\right)$, and the decomposition is suppressed by nitrogen overpressure (Sec. 2.2.5). Thus the failure mechanism of the F-9 element does not seem probable in carbide fuel elements, and for nitride fuel elements such high temperatures are required that other failure mechanisms may be important. The F-9 element failed at very low reactor energy (see Table X) because of the capsule design. The element was thermally isolated in the capsule, so essentially all the energy generated during the transient went to heat the element.

There is little information about postfailure movement of fuel, cladding, and coolant following severe overpower transients on advanced fuel elements. The EBR-II metal fuel element tests indicate that the element environment is very important in determining postfailure movement. Because the static capsule environment of the AI UC Phase II Capsule 1 test bears little resemblance to that of an $r$ erating subassembly, the disposition of the dispersed fuel is also atypical. Severe overpower transients on clusters of advanced fuel elements in a flowing sodium system will be required to understand postfailure movement.

\subsection{Steady State Overpower Operation}

Steady state overpower operation of all the fuel elements in a core can result from reactor overpower operation, but reactor instrumentation is designed to prevent it. Individual subassemblies or elements can also operate at overpower conditions while the reactor is operating normally, because of loading errors (a subassembly or element containing highenrichment fuel loaded into a low-enrichment position in the core). Part of a single element can also operate in an overpower condition owing to misloading of individual fuel pellets (high-enrichment pellet(s) loaded into an element destined for a lowenrichment position in the core). Overpower operation of single elements or a few pellets in an element would be very difficult to detect.

Overpower operation resulting from such loading errors is generally $\langle 150 \%$ of normal power, but it can occur for a significant part of the element life. The immediate results are higher fuel (and, to a smaller extent, cladding) temperatures, and greater cladding heat flux. Higher fuel temperatures can increase fuel swelling and fission gas release from the fuel and melt the fuel, given very high overpower conditions. Advanced fuel element peak fuel temperatures are weil below the fuel melting point during normal operation, so fuel melting is no problem during mild overpower operation. The ultimate consequences of steady state overpower operation are mainly reduced element life and the effects on adjacent elements or subassemblies.

No safety-oriented steady state overpower irradiations have been performed on advanced fuel elements, but during irradiation testing, some elements have been irradiated at peak linear powers above the $80.85 \mathrm{~kW} / \mathrm{m}$ of present, and $100 \mathrm{~kW} / \mathrm{m}$ of probable future, interest. Three sodium-bonded elements of uranium-plutonium carbide fuel and LMFBR design have been irradiated at $130 \mathrm{~kW} / \mathrm{m}$, and six sodium-bonded elements of uraniumplutonium nitride fuel, also of LMFBR design, have been irradiated at 110 to $120 \mathrm{~kW} / \mathrm{m}$, all as encapsulated tests in EBR-II. ${ }^{5,49}$ The three carbide elements had failed when examined at about 3.6 at." $"$ burnup. An interim examination at about 2.7 at. $\%$ burnup indicated that they probably had failed already. Only one has been completely examined. It had failed most severely as determined from radiographs. The cladding, and possibly the fuel, had melted, owing to blanketing of the cladding by 
fission gas released to the sodium annulus between the cladding and the capsule wall after initial cladding failure. This mechanism for progression from initial to severe failure in encapsulated elements has been described, with substantiating evidence, elsewhere ${ }^{49}$ and has been observed in many failed elements. Two of the sodium-bonded nitride elements $(110 \mathrm{~kW} / \mathrm{m})$ had failed at 5.6 at.\% burnup, and four $(110$ to $120 \mathrm{~kW} / \mathrm{m})$, at approximately 2.7 at. ; burnup. Only three of these elements have been completely examined. Melted cladding was observed in one and severely cracked cladding in others. The failure severity was again attributed to gas blanketing.

GUNF irradiated a series of sodium- and heliumbonded elements with uranium-plutonium carbide fuel and LMFBR design in the thermal flux General Electric Test Reactor (GETR) as part of a loss-ofsodium bond test. ${ }^{50,51}$ These tests are discussed in more detail later (Sec. 3.4.1), but they are of some interest here as the elements operated at a nominal peak linear power of $150 \mathrm{~kW} / \mathrm{m}$. Two of the elements had good sodium bonds; one was irradiated for $1 \mathrm{~h}$, the other for $24 \mathrm{~h}$. The elements showed little or no change due to the irradiation. Four helium-bonded elements with diametral gaps of $0.15,0.25,0.38$, and $0.51 \mathrm{~mm}$ were also irradiated for $1 \mathrm{~h}$. The two smaller gaps are typical of LMFBR design; the larger ones are not. None of the elements failed, but cracking, grain growth, and fuel restructuring were observed in ail four. There were a few indications of fuel melting in the element with the $0.38-\mathrm{mm}$ gap and many in the element with the $0.51-\mathrm{mm}$ gap.

A number of encapsulated advanced fuel heliumbonded elements of LMFBR design have been irradiated in EBR-II at peak linear powers of 90.100 $\mathrm{kW} / \mathrm{m} .{ }^{5}$ Both nitride and carbide fuel have been tested. Few of these elements have been examined yet, and some are still being irradiated. One uranium-plutonium carbide fuel element which operated at about $90 \mathrm{~kW} / \mathrm{m}$ reached a goal of 11 at. burnup without failure, and three uraniumplutonium nitride elements operating near 100 $\mathrm{kW} / \mathrm{m}$ have reached 6 at. ${ }^{\circ}$. burnup without failing. There were no significant behavior differences from elements operating at lower linear power.

Assessment of steady state overpower operation of advanced fuel elements indicates that neither helium- nor sodium-bonded LMFBR elements of current design have severe problems (such as fuel melting on startup) below $150 \mathrm{~kW} / \mathrm{m}$. The GUNF tests in GETR showed this to be true. Overpower operation's effect on the lifetime of both helium- and sodium-bonded elements is uncertain. Although high-powered sodium-bonded elements generally failed at low burnup, some 80 - to $90-\mathrm{kW} / \mathrm{m}$ sodium- bonded elements also have failed at similar burnups. The actual failure mechanism has not been established, largely because the progression from initial to severe failure in the encapsulated tests destroyed any indications of the initial failure. When one or more initial failure mechanisms have been established for steady state operation, the effect of overpower operation can be assessed.

There are no data on how overpower operation affects adjacent elements. All the high-power EBR. II elements discussed above were irradiated in A-19 subassemblies that provide separate coolant flow tubes for each element, effectively isolating them from each other.

\subsection{Loss of Sodium Bond}

Partial or complete loss of sodium bond from an advanced fuel element leads tir fuel overheating (Sec. 2.2.6). Liquid sodium in the bond provides a high thermal conductance path from the fuel to the cladding. However, if liquid sodium is replaced by sodium vapor or gas from the plenum above the bond, the thermal conductance of the bond region drops by about an order of magnitude and the immediate consequence is fuel overheating. A partial bond loss such as a bubble in the bond may produce only local overheating with increased fuel gwelling and fission gas release. A large bubble or complete bond loss could lead to fuel melting (or nitride decomposition).

Small gas bubbles may be present in a sodium bond at fabrication. Bond bubble and shrinkage void detection (by eddy current techniques) is sensitive enough to detect bubbles larger than about $1 \mathrm{~mm}$. ${ }^{52}$ Fortunately, bubbles this size or smaller affect fuel temperatures only minimally. During irradition, fission gas released from the fuel normally makes its way to the plenum, but it can be held up in relatively stable gas bubbles in the bond. 53,54 Gas bubbles trapped under the edges of offset pellets can be particularly stable. Thus, although a sodium bond may be free of gas bubbles at fabrication, they can form during irradiation. As the fiel surface covered by a bubble increases, the fuel temperature near the buhble increases. Bubbles can reach a size (critical bubble size) at which the fuel surface in contact with liquid sodium next to the bubble is above the local sudium boiling temperature. Possibly. when this happens the bubble grows and voids the entire bond. ${ }^{19,20}$ No direct experimental confirmation of this mechanism is available.

A. number of things can cause complete loss of sodium bond. Bond sodium boiling and ejection can occur during an overpower or loss-of-flow transient. 
These situations are not discussed here, as they are covered in Secs. 3.2 and 3.5.1. A likely cause of bond loss is ejection of bond sodium through a cladding failure into the coolant. ${ }^{55}$ Bond loss could occur slowly over hours or days or rapidly within a few seconds depending mainly on the size of the cladding failure and secondarily on the pressure inside the element. Sodium from the entire fuel column length or any part of it can be lost, depending on the axial location of the cladding failure. Complete sodium bond loss over some axial fuel length without prior cladding failure is aiso possible if a critical bond bubble size is reached or the bond is displaced by released fission gas (Sec. 3.2.1). Whether bond sodium displaced up into the plenum remains there or can return to the bond while the element is operating must be determined experimentally (Sec. 3.2.6).

All sodium-bonded elements tested to date have been sealed elements, the cladding was pressuretight. Elements in which the plenum can release gas to the reactor coolant or cover gas through a top vent have been proposed. ${ }^{56}$ Plenum pressure would remain low throughout the life of a vented element. Behavior of the sodium bond in a vented element could depend on the specific vent design. particulariy during accidents involving sodium bond vaporization.

There are two different time scales for concern about loss of the sodium bond. Events that occur during and shortly after bond loss, such as fission gas release from the fuel, fuel melting, or MFCI, could lead to failure propagation to adjacent elements. The long-term behavior of a fuel element following bond loss is also important, as a commercial LMFBR wili probably not shut down for each fuel element failure. Assuming that the short-term hehavior is benign (fuel melting, slumping to contact the cladding, and resolidification), the element must survive an additional few atomic per cent burnup until the next scheduled refueling. Chemical interactions between the once-molten fuel and the cladding could be important in the long run, especially if shroud tubes melted after the bond loss.

3.4.1 GUNF GETR Tents." GUNF irradiated elements with uranium-plutonium carbide fuel ${ }^{50,51}$ to study the fuel's short-time hehavior with hoth leelium and sodium thermal honds and at very high heat flux and linter power and io determine whet her

-The elements from these tests were examined at I.ASi. The author reviewed the data on file: snme of the runclusions presented in this section were made hy the author. typical advanced fuel element designs have any heat transfer limitations. Table XIII describes the 12 elements tested. The first four, $210-213$, were similar but had increasing halium bond thicknesses. Only the 210 and 211 bond thicknesses $(0.15$ and $0.25 \mathrm{~mm})$ are typical of present advanced fuel elements. These elements were irradiated to define the thermal design limits of helium-bonded elements. The remaining eight elements (214-221) had good, and various types of defective, sodium bonds. Elements 214 and 215 had good sodium bonds. Approximately $25^{\prime \prime} r$ of the fuel column length of element 216 was unbonded, and 217 was $50^{\circ}$ \% unbonded. Element 218 contained adequate sodium, but without the bonding treatment used to remove voids; eddy current inspection before irradiation showed voids up to 3 $\mathrm{mm}$ wide by $20 \mathrm{~mm}$ long. Elements 219 and 220 simulated sodium bond loss early in life by having helium as the thermal bond. Element 221 simulated sodium bond loss after some burnup by reduced bond thickness (to account for fuel swelling) and by having a helium $-25^{\circ} ;$ argon mixture as the thermal bond. Retained fission gas in the fuel was not simulated by this test. All the elements are generally similar to present advanced LMFBR fuel elements except for the intentional defects and design variations noted above, and for the fuel column length of only $100 \mathrm{~mm}$.

All the irradiations were performed in the GETR Trail Cable Facility. GETR is a thermal reactor, and the Trail Cable Fraility is outside the core so power generation in the elements was asymmetric. Radial and circumferential variation of power generation in the fuel was not estimated. Each element was irradiated individually in an uninstrumented capsule. No thermal neutron filters were used. The nominal peak linear power of the elements was 150 $\mathrm{kW} / \mathrm{m}$ with an axial peak: average power generation ratio of 1.5. The cladding heat flux was approximately $600 \mathrm{~W} / \mathrm{cm}^{2}$. Table XIII lists the irradiation time of each elemen:

There are a few comments which are common to the irradiation hehavior of all or most of the elements. There were no cladding failures. The fuel pellets were generally cracked after irradiation, and the fuel showed grain growth and porosity redistribution.

The four helium-bonded elements, 210.213. hehaved very much as predicted. ${ }^{50}$ The calculated beginning-of-Jife fuel centerline temperatures were I670. 2005, 2375. and $>2480^{\circ} \mathrm{C}$ for elements 210,211 , 212. and 213. respertively. The fuel solidus temperature is approximately $23500^{\circ} \mathrm{C}$; the liquidus temperature. $2481^{\circ} \mathrm{C},{ }^{i n}$ No fuel melting was shown by radiography or metallography of 210 and 211 . There were a few indications of fuel molting in 212 
TABLE XIII

GUNF GETR TEST ELEMENTS

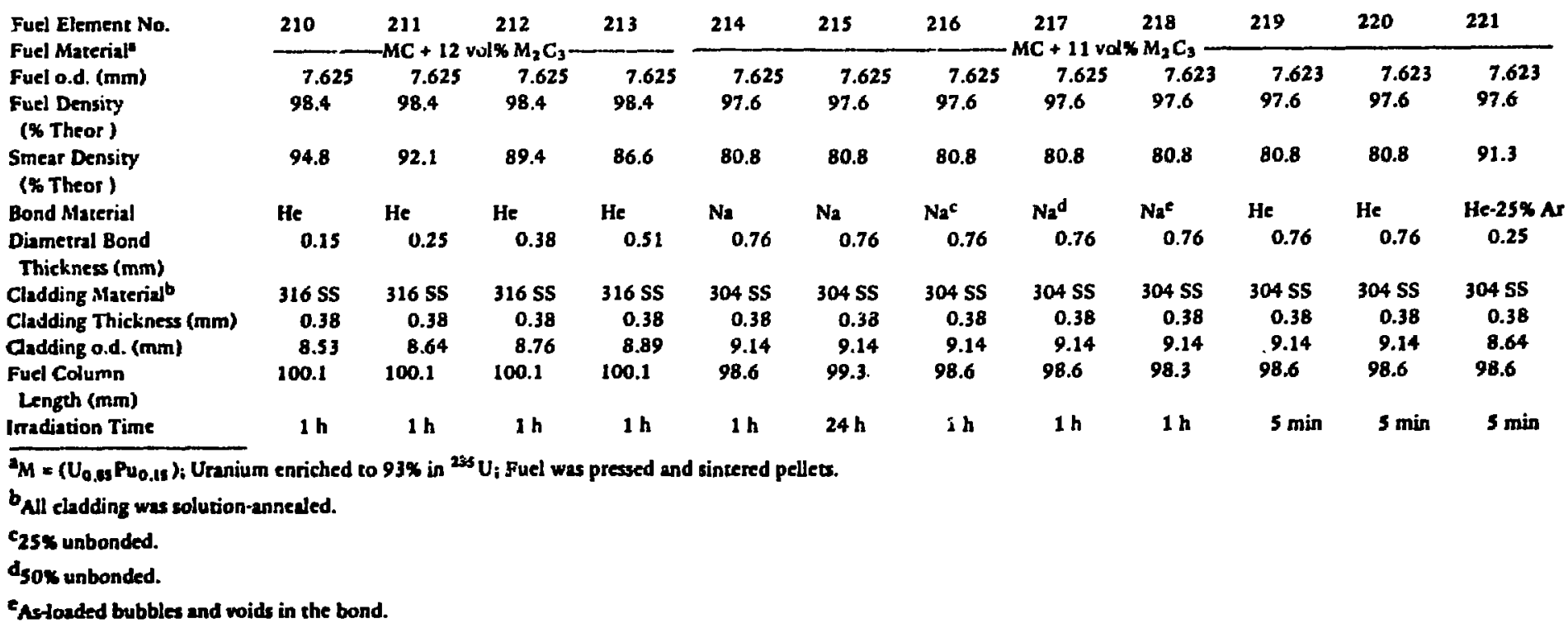


and numerous signs in 213. There was one area of possible fuel-cladding interaction or melted cladding on the cladding i.d. of element 213 . The interaction involved $<0.03 \mathrm{~mm}$ ot he $0.38-\mathrm{mm}$ cladding thickness. Alpis gutoradiographs of sections from 212 end 213 showed high $\alpha$ activity areas, generally at the fuel-cladding interface or at pellet-pellet interfaces near melted regions. This could be associated with uranium-plutonium redistribution caused by melting. Profilometry of all four elements showed cladding deformation in the form of ovalities. Cladding ovalities are probably due to nonaxisymmetric pressure of pieces of fuel on the cladding and they are categorized by the difference between maximum and minimum diameter at a given axial plane. The maximum ovalities of elements 210,211 , and 212 were $0.05-0.1 \mathrm{~mm}$, but 213 showed one large $(0.2-\mathrm{mm})$ ovality and many smaller ones. Element 213 was noticeably bowed after irradiation.

Elements 214 and 215, which had good sodium bonds, performed well. Most fuel pellets from 214 were intact. The cladding of 215 showed some carburization, about $0.03 \mathrm{~mm}$ deep. The $c$ autoradiographs of sections from both elements were uniform.

Elements 216 and 217, various lengths of whose fuel columns were unbonded, behaved similarly. The bond sodium collected at the bottom of each element, leaving the top of the fuel column essentially without sodium. Fuel melting was apparent in the upper half of 216 and the upper two-thirds of 217 . A fuel-cladding interaction or cladding melting occurred on the cladding i.d. of element 217 to a depth of $0.06 \mathrm{~mm}$ out of the $0.38-\mathrm{mm}$ cladding thickness. Profilometry of both elements showed 0.1- to 0.15$\mathrm{mm}$ maximum ovalities, particularly in the upper parts where fuel had melted. Alpha autoradiographs of sections from both elements showed areas of high activity, particularly where fuel had melted. Microprobe examination of a section from 216 indicated cladding carburization, and that the fuel grain boundaries tended to contain more plutonium and less uranium than the grains. The latter fact may relate to the observation that this fuel generally contained sesquicarbide in the grain boundaries between monocarbide grains. Thermodynamic calculations indicate that for (U,Pu)C in equilibrium with $(\mathrm{U}, \mathrm{Pu})_{2} \mathrm{C}_{3}$, the plutonium content is higher and the uranium content lower in the ses. quicarbide phase. ${ }^{58}$

Element 218, which had large voids in its sodium bond, looked like the two elements with good sodium bonds after irradiation.

Elements 219 and 220 simulated complete bond loss at the beginning of life. Both showed signs of fuel melting over the entire fuel column length. Element 221, which simulated a complete bond loss later in life by a smaller gap and lower conductivity plenum gas, showed possible fuel melting. Element 219 showed one small area of interaction where molten fuel had apparently touched the cladding. The penetration was $0.04 \mathrm{~mm}$ of the $0.38-\mathrm{mm}$ clad. ding thickness. Sections from all three elements showed areas of high activity in $\alpha$ autoradiographs. Microprobe examination of a section from 219 show. ed inhomogeneities in the uranium and plutonium content of the fuel in the melted regions and a layer of high plutonium content on the cladding i.d. next to melted fuel. No penetration into the cladding was observed. Cladding ovalities up to $0.1 \mathrm{~mm}$ were seen in the three elements.

\subsubsection{Data From Steady State Irradiation} Tests. Many sodium-bonded fuel elements have been irradiated in steady state irradiation tests. These have incluáea uranium-plutonium carbide and nitride elements $n$ the advanced fuel program and uranium carbide elements in the Large Sodium Graphite Reactor program. This section discusses some observations which are pertinent to sodium bond loss. made during the irradiation and postirradiation examination of some of these elements. In this section evidence for gas bubbles in the sodium bonds of some advanced fuel elements during irradiation is described. In addition, indications of bond loss from two singly clad advanced fuel elements is discussed. Information about the loss of sodium bonds from a number of sodium bonded UC elements is presented, and finally, postirradiation examination data from a severely failed advanced fuel element are mentioned with respect to the long term irradiation behavior following sodium bond loss.

Metallographic sections from a number of encapsulated advanced fuel elements, irradiated in EBRil. have shown asvmmetric areas of high grain boundary swelling or of depleted fission product activity in $\beta \cdot \gamma$ autoradiographs. ${ }^{5}$ It has been postulated that both result from relatively stable gas bubbles in the sodium bond during irradiation. Table XIV lists the parameters of six of these elements. They are generally typical of present sodium-bonded advanced fuel test elements, except that none have shroud tuhes. Heat transfer calculations were performed for an element, part of whose sodium bond was replaced hy a gas bubble. The shapes of the high-temperature fuel areas under the hubbles compared well with those of the high swelling areas shown by postirradiation examinations. This agreement is reasonable if one assumes that grain boun. dary swelling occurs above some critical 


\section{DESIGN AND IRRADIATION PARAMETERS OF ADVANCED FUE!. ELEMENTS SHOWING EVIDENCE OF BOND BUBBLES}

\begin{tabular}{|c|c|c|c|c|c|c|}
\hline Fuel Element No. & U191 & U194 & U195 & K36B & $W E: F$ & B 2-2 \\
\hline Fuel Material ${ }^{a}$ & MC & $\mathrm{MC}+10 \% \mathrm{M}_{2} \mathrm{C}_{3}$ & $\mathrm{MC}+10 \% \mathrm{M}_{2} \mathrm{C}_{3}$ & MC & $\mathrm{MC}+5 \% \mathrm{M}_{2} \mathrm{C}_{3}$ & MN \\
\hline Fuel o.d. (mm) & 6.15 & ธ.07 & 6.07 & 6.73 & 6.37 & 6.47 \\
\hline Fuel Density (\% Theor) & 92 & 98 & 98 & 90 & 94 & 94 \\
\hline Smear Density (\% Theor ) & 73 & 76 & 76 & 81 & 78 & 81 \\
\hline Bond Marerial & $\mathrm{Na}$ & $\mathrm{Na}$ & $\mathrm{Na}$ & $\mathrm{Na}$ & $\mathrm{Na}$ & $\mathrm{Na}$ \\
\hline Diametral Bond Thickness $(\mathrm{mm})$ & 0.76 & 0.84 & 0.84 & 0.38 & 0.64 & 0.51 \\
\hline Cladding Material $^{\mathbf{b}}$ & 304 SS & 304 SS & 304 SS & $316 \mathrm{SS}$ & $316 \mathrm{SS}$ & 316 SS \\
\hline Cladding Thickness (mm) & 0.41 & 0.42 & 0.42 & 0.26 & 0.31 & 0.52 \\
\hline Cladding o.d. (mm) & 7.72 & 7.75 & 7.75 & 7.62 & 7.62 & 8.01 \\
\hline Fuel Column Length (mm) & 343 & 343 & 343 & 343 & 241 & 254 \\
\hline Peak Linear Power $(\mathrm{kW} / \mathrm{m})$ & 84 & 81 & 83 & 82 & 83 & 93 \\
\hline Burnup (at.\%) & 4.50 & 4.64 & 4.94 & 5.85 & 5.82 & 5.48 \\
\hline
\end{tabular}

temperature. Then, the boundary between regions of high and low swelling should parallel isotherms in the fuel. Such eyidence has been found in at least 10 advanced fuel element sections. Bubbles covering as much as $120^{\circ}$ of the fuel surface have been identified. If voids or bubbles of this size had been present at fabrication, they would have been detected easily. Therefore, they probably result from fission gas accumulated during irradiation, particularly under the edges of offset peliets. ${ }^{54}$ Although gas bubbles in sodium bonds cause higher fuel operating temperatures and greater fuel swelling, there is no known correlation between bubbles and element failure.

Two unshrouded fuel elements from the "U5100 Singly Clad Carbide Experiment" have been returned to LASL for examination. ${ }^{5,52}$ Table XV describes the elements and their EBR-Il irradiation. Element U. 248 failure at 3.1 at. $\%$ burnup was indicated at EBR-II by release of bond sodium containing fission products into the reactor coolant. Activity release was slow, occurring over 2 days. The reactor was shat down during most of this time. ${ }^{59}$ The failed element was identified by a 4-g weight loss: about the weight of the sodium originally loaded inso it. The failure point was about $75 \mathrm{~mm}$ below the top of the 340 - mm-long fuel column; this was the only cladding failure. When the element was sectioned for metallography, no sodiun was found in the bond region, either above or below the failure. A specific attemnt was made to detect sodium below the fuel column, around the lower insulator pellet and bottom end plug, but none was found. The fuel above the failure point exhibited grain boundary swelling not seen in that below the failure. No fuel melting was indicated. It has been postulated that the element operated at power for some time after the sodium in the bond above the failure was lost, but that the bond sodium below the failure was lost during the cooling period in the reactor or later. ${ }^{52}$ No mechanism for the loss of sodium below the failure point has been proposed.

TABLE XV

\section{U246 AND U248 ELEMENT DESIGN}

Fuel Element No.
Fuel Material ${ }^{\mathrm{a}}$
Fuel o.d. (mm)
Fuel Density (\% Theor.)
Smear Density (\% Theor.)
Bond Material
Diametral Bond Thickness (mm)
Cladding Material $\mathrm{b}$
Cladding Thickness (mm)
Cladding o.d. (mm)
Fuel Column Length (mm)
Peak Linear Powet (kW/m)
Burnup (at.\%)

\begin{tabular}{|c|c|}
\hline 11246 & U248 \\
\hline$-(\mathrm{U}$ & ) \\
\hline 6.71 & 6.33 \\
\hline 93 & 93 \\
\hline 82 & 73 \\
\hline $\mathrm{Na}$ & $\mathrm{Na}$ \\
\hline $\begin{array}{r}0.43 \\
31655\end{array}$ & $\begin{array}{r}0.81 \\
31655\end{array}$ \\
\hline 0.37 & 0.37 \\
\hline 7.87 & 7.87 \\
\hline 340 & 340 \\
\hline 109 & 109 \\
\hline 3.1 & 3.1 \\
\hline
\end{tabular}

\footnotetext{
${ }^{a}$ Fuet was pressed and sintered pellets.

${ }^{b}$ Cladding was solution-annealed.

CIrradiated in EBR-11 in subassembly $\times 156$.
} 
The top four pellets from unfailed element U246 were displaced upward into the plenum as shown by radiographs taken when the subassembly was disassembled to remove element U248. These elements had no hulddown device on top of the fuel, so the fuel could move upward once the bond sodium melted. At no time was the element inverted while the sodium was molten. The fuel in all metallographic sections showed grain boundary swelling, and it was al most touching the cladding. Special burnup and $\gamma$ scan measurements of the displaced pellets, to determine how long they operated above the core, gave inconclusive results. It has been suggested that this element operated at power for some time with no sodium in the bond region. ${ }^{52}$ Sodium was present before irradiation (as shown by radiographs and eddy current tests), and some was found around the fuel during postirradiation sectioning. This may be an example of fission gas bubbles in the sodium bond reaching critical size and voiding the entire bond. ${ }^{19,20}$ The upward pellet displacement could have occurred during the bond voiding.

Examination of elements U246 and U248 is still in progress, so the above comments and conclusions are preliminary.

GUNF ran a series of four test element irradiations in the GETR to demonstrate sodiumbonded advanced fuel elements performance at high burnup. ${ }^{60^{*}}$ Table XVI lists the element parameters. The elements are similar to present advanced fuel elements. The irradiations were carried out in the GETR V-RAFT facilities in instrumented capsules. Six thermocouples were attached to the cladding of each element. Radiography and metallography of element 125 showed fuel melting attributed to sodium bond loss. Cladding penetration was 0.05 $\mathrm{mm}$ of the $0.38-\mathrm{mm}$ total thickness where molten fuel touched it. The other elements showed no fuel melting. Fission gas release from element 125 was much higher than that from its companion elements (see Table XVI). This release was attributed to the fuel melting. In spite of the fuel melting, the cladding did not fail, as no fission gas was found outside the element. Element 125 may also be an example of fission gas bubbles in the sodium bond reaching critical size and voiding the entire bond. No indications of when bond voiding and fuel melting occurred were reported.

Two encapsulated fuel elements being irradiated in the Materials Test Reactor as part of the AI Large

*The elements from this test were examined at LASL. The author reviewed the data on file. Some of the conclusions presented about those elements are the author's.
Sodium Graphite Reactor program lost their sodium bonds during normal steady state irradiation. ${ }^{61-65}$ The elements had 12.7 -mm-diam by $460-\mathrm{mm}$-long cast UC fuel slugs, sodium-bonded to $14.3-\mathrm{mm}-\mathrm{o}$.d. by $0.25-\mathrm{mm}$-thick 304 stainless steel cladding. They were operating at approximatley $120 \mathrm{~kW} / \mathrm{m}$, and were at 17 000-18 000 MWd/MTU ( $\sim 2$ at. Cr burnup) when they failed. Bond loss was indicated by increased central fuel thermocouple output which went off-scale $\left(1200^{\circ} \mathrm{C}\right.$ ) for both elements. The elements operated for 8-12 h after initial bond loss indications. Peak fuel centerline temperatures were calculated to be above $1700^{\circ} \mathrm{C}$ after bond luss. Examination indicated that one element (NAA-81-2) completely lost its sodium bond and the other (NAA-81-4) was unbonded over the upper $200 \mathrm{~mm}$ of its fuel column. There was no central fuel melting, but the UC and tantalum central thermocouple well interacted. Gross fuel swelling was observed; fuel density decreased 3 to $22 \%$. An attempt was made to locate the cladding failure in NAA-81-2. A leak was located in the upper end plug weld, but no other leaks were found. It was postulated that a leak near the lower end plug weld allowed the bond sodium to be lost into the capsule.

Another series of UC elements that AI tested as part of the Large Sodium Graphite Reactor program also showed signs of sodium bond loss during steady state irradiation. ${ }^{61.66}$ The multielement capsules, EXP-NRX-85-1, 2, and 3, were irradiated in the NRX Reactor at Chalk River, Canada. Each had 12.4-mm-diam by $63.5-\mathrm{mm}$-long cast UंC fuel slugs, sodium-bonded to $14.3-\mathrm{mm}-\mathrm{o} . \mathrm{d}$. by $0.3-\mathrm{mm}$-thick 304 stainless steel or $\mathrm{Nb}-1 \% \mathrm{Zr}$ cladding. The fuel ranged from hypostoichiometric in some elements to hyperstoichiometric in others. The elements were designed to operate at approximately $120 \mathrm{~kW} / \mathrm{m}$. but burnup da:a show they operated at $145-150 \mathrm{~kW} / \mathrm{m}$. Burnup of all elements was approximately 2 at. ${ }^{\prime} i$. The cladding of the four elements in the EXP-NRX. 1 capsule, and four of the six elements in the EXP. NRX-3 capsule failed. Results from the other capsule were not reported. The two unfailed elements in EXP-NRX-3 were the only ones with hyperstoichiometric fuel and $\mathrm{Nb}-1 \% \mathrm{Zr}$ cladding. It was postulated that the sodium bond boiled from the region between the fuel and cladding and condensed in the relatively cold plenum above the fuel in all the elements, because of the higher than expected operating power. NaK coolant from outside all the failed elements mixed with the bond sodium to form an alloy that was liquid at room temperature. This alloy was found in the bond region. In one unfailed element from EXP-NRX-3, bond sodium was found frozen to the top end cap, indicating sodium transfer out of the bond. All elements showed excessive fuel 
TABLE XVI

DESIGN AND IRRADIATION PARAMETERS OF GUNF ELEMENTS 125 TO 128

\begin{tabular}{|c|c|c|c|c|}
\hline Fuel Element No. & 125 & 126 & 127 & 128 \\
\hline Fuel Material ${ }^{a}$ & MC & MC & $-M C+1$ & $\mathrm{C}_{3}-\ldots$ \\
\hline Fuel o.d. (mn) & 6.10 & 6.10 & 6.10 & 6.10 \\
\hline Fuel Density (\% Theor) & 93 & 93 & 97 & 97 \\
\hline Smear Density (\% Theor) & 74 & 74 & 77 & 77 \\
\hline Bond Material & $\mathrm{Na}$ & ria & $\mathrm{Na}$ & $\mathrm{Na}$ \\
\hline Diametral Bond Thickness (mm) & 0.76 & 0.76 & 0.76 & 0.76 \\
\hline Cladding Materialb & Incoloy 800 & 304 SS & Incoloy 800 & 304 SS \\
\hline Cladding Thickness (mm) & 0.38 & 0.38 & 0.38 & 0.38 \\
\hline Cladding o.d. (mm) & 7.62 & 7.62 & 7.62 & 7.62 \\
\hline Fuel Column Length (mm) & 340 & 340 & 340 & 340 \\
\hline Peak Linear Power $(\mathrm{kW} / \mathrm{m})$ & 82 & 82 & 82 & 82 \\
\hline Burnup (at.\%) & 5.0 & 5.1 & 4.9 & 5.2 \\
\hline Fission Gas Release $(\%)$ & 35 & 12 & 3 & 5 \\
\hline
\end{tabular}

swelling and high fission gas release with up to $30 \%$ density decreases. The experiment was designed for peak fuel temperatures of $1000-1200^{\circ} \mathrm{C}$. Actual temperatures as high as $1400^{\circ} \mathrm{C}$ were calculated if the sodium bond iemained, and temperatures over $1700^{\circ} \mathrm{C}$ were estimated if the bond was lost. The high fuel swelling and gas release were attributed to these high temperatures. Metallography gave evidence of molten uranium (in the hypostoichiometric fuel) near the centerline of some fuel slugs. The UC did not melt. Cladding failure was ascribed to the gross fuel swelling. No estimate of when the initial bond loss occurred or how long the elements may have operated in an unbonded condition was made.

A severely failed encapsulated fuel element (K49), irradiated in EBR-I, has been examined at LASL. ${ }^{49}$ (See also Sec. 3.3.) The cladding had melted in several areas owing to gas bubbles between cladding and capsule. Cladding components ( $\mathrm{Fe}, \mathrm{Cr}$, $\mathrm{Ni}$ ) were dispersed throughout the fuel. Fuel melting may have occurred also. The cladding and fuel mixture contacted the 304 stainless steel capsule wall in several places when it was hot enough to deform into the shape of the capsule wall. Microprobe examination of these areas showed no penetration of plutonium or uranium into the wall. No capsule wall melting was seen. This element was at 3.6 at."' burnup when examined, but indications of failure were seen in a neutron radiograph taken at about 2.7 at. $"$; burnup. ${ }^{52}$ The cladding probably melted between
2.7 and 3.6 at. $\%$ burnup, but it cannot be established exactly how long the element operated thereafter.

3.4.3 EBR-II Metal Fuel Tests. Loss of sodium bond tests have been conduted on EBR-I driver fuel elements $^{67-70}$ to provide guidance for analysis of elements that have no sodium bond between fuel and cladding or lose the bond on reactor startup. The elements were like those used for the transient overpower tests (see Sec. 3.2.5 and Table XI), except that the sodium bond was replaced by argon.

Two tests were run in TREAT using the Mark I integral sodium loop with flowing sodium coolant. ${ }^{67-69}$ The single element in each test was surrounded by six dummy elements at the same element spacing used in EBR-II. No thermal neutron filter was used, but the axial power was shaped by absorbers. Instrumentation included coolant inlet flow and pressure measurement, and coolant inlet and outlet temperature measurement.

Both tests used TREAT flattop transients. In test ID-RP-1, a peak linear power of $36 \mathrm{~kW} / \mathrm{m}$ was sustained for $6.9 \mathrm{~s}$; in test ID-RP-2, $57 \mathrm{~kW} / \mathrm{m}$ for 6.2 $\mathrm{s}$. The peak linear power of an element in EBR-II is approximately $32 \mathrm{~kW} / \mathrm{m}$. The sequence of fuel melting, slumping of molten fuel to contact the cladding, and resolidification of the fuel occurred. Peak fuel temperatures were calculated to be approximately $1100^{\circ} \mathrm{C}$. No cladding failures were found, and the cladding dimensions were still within 
the EBR-II specification after the tests. Fuel slumping and prominent voids in the fuel were found. The molten fuel reacted with the cladding in both elements.

The calculated coolant outlet temperatures rose sharply after molten fuel touched the cladding; the measured temperatures did not. The mociel deficiency that caused this difference was thought to be the assumed coherent slumping of the entire fuel column length.

Another loop test with a partially bonded element ${ }^{70}$ confirmed calculations that, in the more realistic case of incomplete sodium loss, the metal fuel would not melt upon loss of a large part of the bond. Further, in this case, partial sodiun loss did not cause failure through generation of high local pressures from vaporization of the sodium remaining in the bond.

3.4.4 Discussion. Experimental information about the consequences of sodium bond loss covers a useful range of accident conditions. At the mild end of the range, evidence of smail gas bubbles in the sodium bonds of advanced fuel elements is availat le from steady state irradiations (Sec. 3.4.2). In all probability, these bubbles contain fission gas, released from the fuel, which accumulates during irradiation. Although bond bubbles raise local fuel temperatures which, in turn, increase local fuel swelling and fission gas release, sodium-bonded fuel element failure has not yet been related to their presence.

Shroud tubes may affect the existence and consequences of small gas bubbles in a sodium bond (Sec. 2.2.7). Shroud tubes keep the fuel pellets aligned and prevent individual pellets or pieces of pellets frum moving about in the large gaps in sodiumbonded elements. Thus, they should provide few locations (such as under offset pellets) for fission gas to collect during irradiation. Although the incidence of bond bubbles in shrouded elements should be low, their consequences may be great. Gas bubbles collecting between the shroud tube and the cladding can cause melting of the shroud tube, and molten tube material (usually stainless steel) can form lowmelting eutectics with the fuel. Although this sequence may not present a short-term problem, an interaction between any shroud and fuel eutectic and the cladding could reduce the life of the element. No postirradiation examinations of sodium-bonded elements with shroud tubes have been performed, so there is no experimental evidence to substantiate or refute these speculations.

Whether a large enough gas bubble in a sodium bond can become unstable and grow to void the en- tire bond by local sodium boiling is difficult to say. Preliminary examination of element U246 and the GUNF and EXP-NRX irradiations indicates that this may have happened (Sec. 3.4.?). Further analysis of U246 may supply more information, but additional testing, particularly out-of-pile experiments, is needed.

In two sodium-bonded fuel elements that failed (U248 and NAA-81-2), the sodium bond was lost below any known failure point as well as above (see Sec. 3.4.2). In both cases, attempts were made to find a lower failure point but none was found. There are mechanisms by which a small failure can plug, so one cannot state absolutely that lower failure points did not exist in these elements. The question of whether sodium bond loss can occur below a cladding failure deserves investigation.

For severer accidents, such as complete sodium bond loss, there are enough experimental data to indicate that an element's short-term behavior may be no problem. A qualitative understanding of the behavior following bond loss is available from the GUNF GETR tests and the EBR-M metal fuel tests of unirradiated elements. The sequence of events initiated by reduced thermal conductance of the bond region is fuel melting, fuel slumping out to contact the cladiding and reestablish high thermal conductance, and resolidification of the fuel. Too little quantitative understanding of element behavior is available to model and predict fuel, cladding, and coolant temperatures following bond loss. In particular, fuel-cladding interface heat transfer coefficients upon contact by molten and later solid fuel are not known. Instrumented tests will be necessary to determine this parameter.

Much less information is available about the behavior of irradiated elements following sodium bond loss. The results from the UC elements and U248 suggest that after sufficient burnup, the fuel may not melt (see Sec. 3.4.2). The irradiated fuel swells out to contact the cladding during overheating. Apparently the bond loss from these elements was very slow, allowing enough time for fuel swelling. A knowledge of the kinetics of fuel swelling as a function of temperature would be required to determine whether there is enough time for the fuel to swell and prevent melting during a rapid bond loss. Bond loss experiments on irradiated elements or out-of-pile tests on irradiated fuel swelling kinetics are needed to resolve this question.

There is no experimental information about sodium bond loss in nitride fuel elements. Much can be inferred from the similarities of nitride and carbide properties, but if the nitride fuel reaches high enough temperatures to allow decomposition, significani behavior differences can be expected. 
There is little information about the long-term irradiation behavior of sodium-bonded elements following bond loss. Melting and dispersal of cladding throughout the fuel, and contact of the possibly molten fuel-claciding mixture $\because$ ith the capsule wall in the K-49 fuel element simulates what might occur following bond loss in a sodium-boncied element with a shroud tube (see Sec. 3.4.2). The lack of attack on the capsule wall is promising, but, unfortunately, it is not known how long the fuel-cladding mixture contacted the capsule wall. To establish how bond loss affects element lifetime, irradiation tests which simulate bond loss with carbide and nitride fuel, with and without shroud tubes, and with various types of cladding will be required.

\subsection{Other Safety Aspects}

Many other aspects of advanced fuel elements require safety research, but essentially no work has been done. Three important areas are loss of coolant accidents, molten fuel-coolant interaction, and failure propagation.

3.5.1 Loss of Coolant. Loss of coolant or loss of flow is usually considered the most probable major accident that can happen to a fuel element. This generic class covers a large variety of specific accidents. Loss of electric power to the sodium pumps causes a relatively slow flow coastdown $(\sim 10-\mathrm{s})$ for the entire core. ${ }^{22}$ Blockage of a subassembly inlet or an element flow channel can cause local loss of coolant ${ }^{71}$ in $\sim 1 \mathrm{~s}$ or less. A third postulated loss of coolant accident, blanketing of an element by fiscion gas released from a cladding failure in an adjacent element, ${ }^{72}$ can occur in milliseconds. The severity of loss of flow accidents also ranges widely. Very mild flow perturbation followed by reactor scram is a high-probability accident covered by the plant protective system. Loss of flow can also be assumed to initiate design basis accidents.

Loss of flow represents loss of element cooling capacity. In many postulated loss of flow accidents, the fuel power generation remains approximately constant for some time (up to a few seconds), followed by a reactor scram. ${ }^{22}$ The fuel centerline temperatures drop after the scram, but the coolant and cladding temperatures continue to rise for some time, depending on the actual variation of power and flow with time. The net result of this transient is that the peak fuel temperatures are essentially unaffected, but fuel surface, cladding, bond, and coolant temperatures rise above their normal operating range.
Many of the consequences of a loss of flow accident with advanced fuel elements will resemble those with oxide fuel elements. In particular, the cladding and coolant overheating will be similar, but probably severer owing to the shorter thermal time constants of advanced fuel elements which allow faster heat transfer during transients. Larger and faster coolant temperature variations in an advanced fuel core compared to an oxide fuel core can also cause greater thermal stresses in core structural components. Sodium-bonded alements will cause more concern than helium-bonded elements because of their very short thermal time constants. The bond behavior in sodium-bonded elements will be critical in determining the outcome of an accident. Questions, such as whether the bond sodium or coolant sodium will boil first and how much superheat will be required, must be answered for a number of element conditions such as beginning and end of life.

Unfortunately, there have been no loss of flow tests of advanced fuel elements, probably because of the greater complexity and expense of tests using a controlled flow coolant. There have been many loss of flow tests with oxide elements. ${ }^{2}$ Some information about postfailure fuel relocation in advanced fuel elements might be obtained from these oxide tests, but little of the failure threshold and failure mechanism data would be applicable.

3.5.2 MFCI. Vapor explosions in various systems have been studied. ${ }^{73,74}$ For the LMFBR, the possibility of a vapor explusion initiated by MFCI or a molten cladding-coolant interaction is particularly important. Although molten oxide fuel and sodium coolant interaction has been studied, the basic energy transfer mechanisms and rates are still uncertain. ${ }^{73}$ Many mechanisms for rapid transfer of energy from molten fuel to the sodium have been proposed. These include various fragmentation and entrapment mechanisms for generating a high surface area in the fuel, and postulated high sodium superheat with homogeneous nucleation of the sodium.

Essentially no experimental data on MFCI in advanced fuels are available. Their complexity makes it difficult to determine whether the mechanisms that operate with oxide fuel apply to advanced fuels. The most significant difference between oxide and advanced fuels is probably the latter's much higher thermal conductivity (see Sec. 2.2.1). If heat transfer through the fuel is a rate-controlling step in MFCI, ${ }^{74}$ advanced fuels may exhibit higher energy transfer rates than oxide fuels, and thus severer MFCI. If a vapor film between the molten fuel and liquid 
sodium controls heat transfer rates, the thermal condu.iivity difference may be inconsequential. If fragmentation is important in MFCI, the different mechanical properties of oxide and advanced fuels may also cause different behavior. ${ }^{75}$

MFCI has been investigated by dropring molten UC into liquid sodium, ${ }^{76}$ but no useful data were obtained owing to experimental difficulties. The AI UC Phase II Capsule 1 transient overpower test (Sec. 3.2.3) was far from an optimum test for MFCI, so the fact that only moderate pressures were observed in the capsule after fuel melting cannot be used as more than an indication about advanced fuel MFCI. The only conclusion that can be drawn is that MFCI experiments with advanced fuels are needed to establish whether it is a significant problem.

3.5.3 Failure Propagation. The question of whether failures or accidents in an LMFBR can propagate from element to element or subassembly to subassembly has been studied extensively. Within a subassembly, the basic question is whether initially small local faults can grow to affect the entire subassembly. Mechanisms proposed for element-toelement failure propagation ${ }^{77}$ include fission gas release to cause gas blanketing or mechanical damage to adjacent elements, and fuel release to cause local coolant blockage or, if molten, MFCI. Propagation of failures from one subassembly to the next involves breaching of subassembly duct walls. Both mechanical and thermal loading can be involved. ${ }^{78}$

Although there has been no failure propagation work on advanced fuels, some of the experimental and analytical investigations are applicable. In particular, work that is independent of fuel element design, such as the hydrodynamics of flow blockages and gas blanketing, is of direct use for advanced fuel elements. Features that can affect failure propagation in advanced fuel elements are the high fuel thermal conductivity, sodium bond, and low fission gas release of the fuel.

\section{SUMMARY}

Experiments and experience relative to the safety of advanced LMFBR fuel elements have been reviewed. The design and operating parameters and some of the unique features of advanced fuel elements were discussed briefly. Transient and steady state overpower operation, and loss of sodium bond tests and experience were discussed in detail. Areas where information was lacking were also mentioned. The following sections summarize the major conclusions of the report.

\subsection{Transient Overpower Operation of Sodium- Bonded Elements}

Significant Parameters. The most significant parameters in sodium-bonded element failure are probably maximum fuel temperatures and the amount of molten fuel produced. Others, such as the amount of retained fission gas, may be important for irradiated elements.

Failure Thresholds. Failure thresholds have not been established, but a lower limit of some fuelmelting may be inferred. Other mechanisms such as fission gas release may set failure thresholds for irradiated elements.

Failure Mechanisms. One failure mechanism was deduced for a gross overpower test in a static capsule, (AI UC Phase II, Capsule 1 test); but as the EBR-II metal fuel element tests show, failure mechanisms in static capsules and in flowing sodium coolant may differ. There is no indication that sodium bond vaporization causes high pressures in elements. Vaporized sodium seems to condense in the element plenum. Fission gas release may be significant in irradiated elements.

Sodium Bond Boiling and Ejection. Two different tests indicate essentially no superheat (AI UC tests) and approximately a $100^{\circ} \mathrm{C}$ superheat (BCL Nitride tests) at the start of boiling. Tests of elements with large bond gaps (AI UC tests) indicate that bond ejection and dryout of the bond region do not occur immediately after bond boiling begins. These phenomena may depend on the bond gap size.

Bond Ejection by Fission Gas. Release of retained fission gas has displaced the sodium bond up into the element plenum in one test (Series UL test UL4 ).

Postfailure Fuel Movement. The disposition of fuel and cladding after a gross failure has been determined in a static capsule test (AI UC Phase II, Capsule 1). On the basis of observations from EBR-II metal fuel element tests, different patterns will probably occur in tests with a flowing sodium coolant and a heated environment.

\subsection{Transient Overpower Operation of Helium- Bonded Elements}

Significant Parameters. The most significant failure parameters are probably maximum fuel temperatures or the amount of molten fuel produced 
in helium-bonded elements. The amount of retained fission gas may be important for irradiated elements.

Failure Thresholds. The failure threshold of an irradiated element of a particular design has been estimated (Series UL test UL-3). An unirradiated element of the same design did not fail during a similar transient (Series UL test UL-1).

Failure Mechanism. Failure of an irradiated element (Series UL test UL-3) was probably by cladding rupture due to either differential expansion of the fuel and cladding, fission gas release, or fuel swelling.

\subsection{Steady State Overpower Operation}

Linear Power Limits. No short-term severe problems such as fuel melting on startup have been observed in sodium- or helium-bonded elements of current design at $150-\mathrm{kW} / \mathrm{m}$ linear power. Higher limits may exist, depending on element design. No data are available on limits in sodium-bonded elements with shroud tubes.

Effect on Lifetime. The effect of overpower operation on element lifetime is unknown.

\subsection{Loss of Sodium Bond}

Small Gas Bubbles. The effects of small gas bubbles in sodium bonds have often been observed. The bubbles are probably caused by accumulation of fission gas during irradiation. Although bond bubbles cause higher fuel temperatures and thus greater fuel swelling and fission gas release, small bubbles have not been identified as contributing to element failure. There are no data on the incidence or consequences of gas bubbles in the bonds of elements with shroud tubes.

Critical Bubble Size. Whether a sufficiently large gas bubble in a sodium bond can grow and void the entire bond by local sodium boiling is not known. The results of some steady state irradiations (U246, GUNF, and EXP-NRX experiments) may be interpreri to indicate that it can.

Complete Bond Loss. The sequence of events following complete sodium bond loss is qualitatively understood. Quantitative understanding in terms of modeling and predicting fuel, cladding, and coolant temperatures requires knowledge of the contact heat transfer coefficient between molten and later resolidified fuel and cladding, and knowledge of the behavior and kinetics of fission gas release and fuel swelling in irradiated elements. The fuel has not melted after bond loss in a number of irradiated elements.

Continued Irradiation after Bond Loss. The data are insufficient to tell whether continued irradiation of a fuel element after bond loss could cause safety problems. In one element in which a fuel-cladding mixture contacted the capsule wall for some time, no interactions were observed.

\subsection{Other Safety Aspects}

There is no significant experimental information on other aspects of advanced fuel element safety such as loss of coolant accidents, molten fuel-coolant interactions, and failure propagation.

\section{REFERENCES}

1. G. W. Cunningham, "Advanced Breeder Fuel Development Program," Trans. Am. Nucl. Soc. 19. 83 (1974).

2. "Proceedings of the Fast Reactor Safety Meeting," Beverly Hills, California, April 2-4, 1974, U.S. Atomic Energy Commission reports CONF740401-P1, P2, and P3 (1974).

3. T. W. Latimer et al., "Steady State Irradiation Behavior of Helium-Bonded Uranium-Plutonium Carbide," Trans. Am. Nucl. Soc. 19, 91 (1974).

4. J. O. Barner et al., "Steady State Irradiation Behavior of Sodium-Bonded Uranium-Plutonium Carbide," Trans. Am. Nucl. Soc. 19, $91-92$ (1974).

5. R. D. Baker, Comp., “Quarterly Report, Advanced Plutonium Fuels Program, April 1 through June 30, 1974, and Eighth Annual Report, FY 1974," Los Alamos Scientific Laboratory report LA-5781PR, pp. 15-50 (November 1974).

6. "Fast Reactor Mixed-Carbide Fuel Element Development Program, Fourteenth Quarterly Progress Report, October 1970 through June 1971," Gulf United Nuclear Fuels Corporation report GU5279, pp. 44-51 (November 1971).

7. P. K. Doherty et al., "Optimum Pin Diameter for LMFBR Advanced Fuels," Trans. Am. Nucl. Soc. 19. 87-88 (1974). 
8. B. F. Rubin. "Summary of (U,Pu)O, Properties and Fabrication Methods," General Electric report GEAP-13582 (November 1970).

9. A. B. G. Washington. "Preferred Values for the Thermal Conductivity of Sintered Ceramic Fuel for Fast Reactor Use." U.K. Atomic Energy Authority report TRG-Report-2236. pp. 21.26 (September 19731.

10. C. A. Alexander et al.. "Thermophysical Properties of (U.Pu)N." in Plutonium 1970 and Other Ac. tinides. W. N. Miner, Ed., Proc. th Intern. Conf. Pluronium an!' Other Actinides. Salta Fe. N.M. Octoher 5-9. 1:570. Part I. pp. 95-102.

11. T. N. Washburn and J. L. Scott, "Performance Capability of Advanced Fuels and Fust Breeder Reactors," Oak Ridge National Laboratory report ORNL-TM-3388 (May 1971 ).

12. H. H. Hummel and D. Okrent, Reactivity Coefficients in Large Fast Power Reactors (American Nuclear Society, 1970) . pp. 313-351.

13. E. K. Storns. The Refractory Carbides (Academic Press, New York. 19607), pp. 171-221.

14. R. L. Gibby et al., "Analytical Expressions for Enthalpy and Heat Capacity for Uranium. Plutonium Oxide," J. Nucl. Mater. 50. 155-161 (1974).

15. M. Tokar. A. W. Nutt, and J. A. Leary. "Mechanical Properties of Carbide and Nitride Reactor Fuels." Los Alamos Scientific Laboratory report LA.4452 (October 1970).

16. W. M. Olson and R. N. R. Mulford. "The Decomposition Pressure and Melting Point of Uranium Mononitride." J. Phys. Chem. 67. 952-953 (196:3).

1i. W. M. Olson and R. N. R. Mulford, "The Decomposition Pressure of Plutinnium Nitride." J. Phys. Chem. 68. 1048.1951 (1964).

18. "Quarterly Status Report on the Advanced Plutonium Fuels Program. Aprii 1-June 30. 1967," Los Alarr.ss Scientific Laboratory report LA-374i3MS, pp. $27-28$ (August 1967 ).

19. L. Rutland et al.. "Criticai Bubble Size in Sodium-Bonded Ceramic Fuels," Trans. Am. Nucl. Soc. 10, 471.472 (1967).
20. R. Schonebere and H. Ernst. "Das Verhalt(') von Ginsblasen in den Natriumgebundeenen Kar. bidgefullten Brenstatovi eines Schnellen Bruters." Nucl. Eng. Design 21. 65.71 (1972).

21. J. D. B. Lambert et al. "Purformance of MixedOxide Fuel Elements-ANL. Experience." in Pruc. Cunt. Fast Reactar Fucl Blement Technolong. New Orleuns. Wouisiana. April 13.15. 1971, pp. 517.554.

22. M. D. Carelli. "Fuel Rud Design Limit and Transient Survival Criteria." Westinghususe Flectric Corporation Advanced Reartors Division report WARD.4135-6 (.June 1970).

23. J. Grohm. Fast Reactor Safoly I Academuc Press. New York. 19711. pp. 286-298.

24. J. F. Kerrisk et al.. "Transiem Irralianion Bonavior of Sudium and Helium.Honded Curbides." Trans. Am. Nucl. Sine. 19. 92.93 (1974).

25. "Fist Reactor Mixed-Carbide Fuel Bilement Development Program. Twelfth Quarierly I'rogress: Repon. April through June 1970." United Nuclear Corparation report UNC.5263. pp. 27.29 (Auzust $1970)$.

26. D. L. Keller. "Annual Report. Propress un Development of Materials and Technology for Ad. vanced Reactors During July. 1968. through Junc. 1969." Batcelle Memorial Institute report BMI-1R6s. pp. A.118 to A.126 (.) 1969 ).

27. D. 1. Keller. "Progress on Development of Fucls and Technology for Advanced Reactors During July. 1969. through June. 1970. Annual Report." Battelle Memorial Instilute report BMl-1886, pp. A-72 to A85 (July 197(0).

28. Ibid., july through September. 1970. Prouress Report. BMI-189.1, pp. A-39 to A-4) (October 1970).

29. Ibid.. October through December. BMI-1898, pp. A-133 to A-37 (January 1971 ).

30. Ihid.. July, 1970, through June, 1971, Annual Report. BM1-1918. pp. A-107 to A-117 (July 1971).

31. Ihid.. July, 1971, through June. 1972. Final Report. BMI-1925, pp. A-47 to A-56 (June 1972).

32. A. A. Bauer, Battelle Columbus Lahoratories, private communication, 1974. 
33. S. A. Stachura el al.. "Uranium Carbide Transient Hoating Experiments-Phase 1." Atnmick

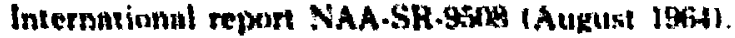

3i. "Annual Technical Progress Report. ABC Unclaskified Prokrams. Fiscal Yoar IGk4." Alomics International report NAA.SR.g9g9. po. I.C.3l iol. C.60 (Auguxl 1964$).$

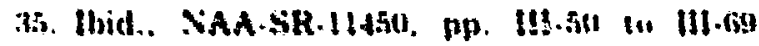
(November lateis!.

i4. Quarterly Technical Protess Kequr. ARC linclassified Erozmons. July.September 1965." Alnmics Internationai neport XAA.St-1!6so, pt 1 , 25) 11 1. .32 (December 19x551.

T., s. J. Stachurn and Mt. Silberherk. "The Applica. tiun of Experimental Data from ThtoAt Moldown Situdios Io Reactor Accident Analysis," in Pros. Cont. Safely. Fuels, and Core Desien in larze fast Nower Reaclots. Arkunne Sational lahoratory

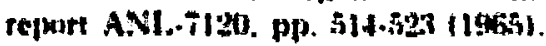

36. A. V. Crewe and 5 , Lawrowski. "Heactor Develingment Prozram Progrest flepart, June 19is." Argonne Nutional takaratury report ANI.7071. p. is (Jutly 1963).

39. F. G. Fonte ot al. "Annual Progress lieport for 1965. Metallurgy Division," Argonne Nitimal

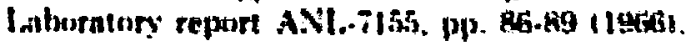

411. 1. Neimark. Argonne National laburatory. privnte communication. 1975.

H. C. F. Diekerman et al., "In.Pile Experiments on Meltdonn of BHR-II Mark I Fuel Flements in Stag. nant Stxium." Nucl. Sci. Frig. I8. 319.328 (1964).

42. C. F. Dickerman ef al.. "TREAT Melidown of Irradiated Mctallic Fast Reactor Fuel in an Inert At. mosphere." Nucl. Appl. 3. 461.473 (1967).

43. C. E. Dickerman et al. "Summary and Analysis of TRFAT Sodium lokp Experiments on Hehatior of Single FBR-1] Mark I Pins Under Accident Con. ditions." Nucl. Eng. Design 7. 442.454 :19681.

H. C. E. Dickerman et al. "Power Pulse Meltdown Experiments Performed in the Mark 1 TREAT Sisdium Loop on Clusters of 7 EBR-II Mark I Type Pins." Nucl. Eng. Design 12. $391-4(16$ (1970).
15. 1. I. Koch et al. "Addendum ta Hazard Sum: mary Heport. Exparimental Breeder Renctor.II 1FBik-11.." Argonne National Laboraton report AN1.63719 (Addendumi (June 1962).

46. R. C. Noyes et al., "Development and Evalun. tion of the Combustion Fistinecrinx Advanced 1000 MV. IAPBR Desion," in Proc. Intem. Conf. Stolium Technoluay and tarke Fast Reactar Desian. Chicatti. Illinais, Sowember 7.9. 1968. Aronnne

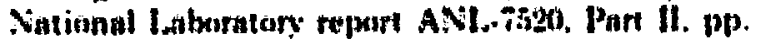

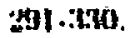

17. Juhn H. Field and Garn H. Thamar. "Fost Rencstar Fucl Faidure Throbulds and Mechanisus." Trans. Am. Nuri. \$ise. 13.719 (1970).

th. R. B. Muratn ol al.. "Friction Factors and Medel for Cias lleleake frum Failed LAFBht Fuel Rods." Cienceal blectric equart CEAP.13949 iswnember lon:th.

49. It. D. Haker. Camp., "Quarterly Rejuift. Ad. sanced thlotonium Pucls Prouram. Apuil I through June 30. 1973, and Seventh Aanunl Reporr. F) 1973." Ias Alamo Scientifie Laburatory report 1.A. 5it90.P1R. pp. 12.35 iseptember 1973).

50. C. Cirando and M. Montenmery. "Safety Analysis Report for Thermal Buhavior Amalysis of Mixed Carbide Irradiation Capsules UNC 2In thrmah ISC 221." Inited Nuclear Corporation repurt t'XC.52n 1May 19 tol.

51. M. H. Momigumen et al., "Topical Report. Fust Meartor Minat Carbide Fuel Element Develupment Program. High Power and Heat Flux Irradiation of liranium.Plutonium Carbides." Guif Uniled Suclear Fuels Corporation report GU.5:294 (April $19 \% 31$.

i2. John Barner, Las Alamos Scientific Laburatory, privnte rommunicntim, 1975.

33. F. H. Nuvendistern and A. A. Bishop. "Temperature Distribution Caused by Gas Bubbles in "Sirdiun Bunded Fuel Rud." Chem. Fungr. Prog. symp. Sur., Vir. 92, Vol. 65. pp. 131-137 (1969).

54. H. O. Shud and A. A. Bishop. "Stationary Gas Bubbles in Narrow liquid-Filled Gaps," Nucl. Appl. Tech. B. 261.275 (1970). 
5i5. J. F. Kerrisk. "The Consequences of Sodium Bund Luss from an LMFBR Carbide Fuel Element," Los Alamos Scientific Laboratory report LA-6095MS (October 1975).

i6. (i. Menzel et al.. "Core Design of CE LMFBR Demonstration Plant." Trans. Am. Nusl. Soc. 14. $71+(1971)$.

5i. J. G. Reavis et al.. "Melting Behavior of (U,Pu) Munocarbides." in Plutonium 1970 and Other Acrinides. W. N. Miner, Ed., Proc. 4th Intern. Conf. Plutonium and Other Actinides, Santa Fe, N.M.. October 5-9. 1970. Part II, pp. 791-798.

58. R. D. Baker. Comp.. “Quarterly Status Report on the Advanced Pluxonium Fuels Program. April I (1) June 3i), 1971 and Fifth Annual Report. FY 197!." Lus Alamos Scientific Laboratory report LA-4749. MS. pp. 46.47 (August 1971 ).

59. John Hoenkamp. Argonne National Laboratory. prisate communication. 1974.

60. M. H. Montgomery et al., "Topical Report, Fast ?eactor Mixed Carbide Fuel Element Development Program, Sodium-Bonded Uranium Plutonium Carbide Fuel Rods Irradiated to 46.000 MWD/T," Gulf (inited Nuclear Fuels Corporation report GU-5306 (November 1973).

6). "Annual Technical Progress Report, AEC Enclassified Programs, Fiscal Year 1964," Atomics International report NAA-SR-9999. pp. I-B-32 to IB.59 (August 1964).

62. “Quarterly Technical Progress Report, AEC Unclassified Programs, July-September 1964, "Atomics International report NAA-SR-10501, pp. II. 16 to II-34 (December 1964).

63. Ibid.. October-December 1964, NAA-SR-10850, pp. II -20 to II-40 (February 1965).

64. Ibid., January-March 1965, NAA-SR-11200, pp. II-25 to II-36 (April 1965).

65. "Annual Technical Progress Report, AEC linclassified Programs, Fiscal Year 1965," Atomics International report NAA-SR-11450, pp. Il-19 to II52 (November 1965).
66. R. D. Hahn, "The High-Temperature Irradiation Behavior of Hypostoichiometric Uranium Monocarbide," Atomics International report NAASR-11134 (August 1965).

67. F. L. Willis et al., "TREAT Experimental Study of Survival of EBR-II Fuel Pin in a Loss-of-Bond Incident," Trans. Am. Nucl. Soc. 11, 698 (1968).

68. C. E. Dickerman et al., "Analysis of Transient Behavior of Unbonded EBR-II Fuel Pin Incident," Trans. Am. Nucl. Soc. 11, 698-699 (1968).

69. C. E. Dickerinan et al., "TREAT Sodium Loop Experiments 0:: Performance of Unbonded, Unirradiated EBR-II Mark I Fuel Elements," Nucl. Eng. Design 12, 381.390 (1970).

70. C. E. Dickerman, "Studies of Fast Reactor Core Behavior Under Accident Conditions," Nucl. Safety 11, 195-205 (1970).

71. M. H. Fontana et al., 'Effect of Partial Blockage in Simulated LMFBR Fuel Assemblies," in Proc. Fast Reactor Safety Meeting, Beverly Hills, California, April 2-4, 1974, U.S. Atomic Energy Commission report CONF-740401-P3, pp. 1139-1160 (1974).

72. J. B. van Erp et al., "An Evaluation of Pin-toPin Failure Propagation Due to Fission Gas Release in Fuel Subassemblies of Liquid-Metal-Cooled Fast Breeder Reactors," Nucl. Eng. Design 31, 128-150 (1974).

73. R. P. Anderson and D. R. Armstrong, "Comparison Between Vapor Explosion Models and Recent Experimental Results," A. I. Ch. E. Symp. Ser. No. 138, Vol. 70, pp. 31.47 (1974).

74. H. J. Teague, "Summary of Papers Presented at the CREST Meeting on Fuel-Sodium Interaction at Grenoble in January 1974 and Rapport of Conference Papers $38 \mathrm{a}-\mathrm{k}$ on Fuel-Sodium Interaction," D. Faude, Ed., Proc. Intern. Conf. Engineering of Fast Reactors for Safe and Reliable Operation, Karlsruhe, October 9-13, 1972, Vol. II, pp. 812-838.

75. A. W. Cronenberg et al., "A Thermal Stress Mechanism for the Fragmentation of Molten $\mathrm{UO}_{2}$ Upon Contact with Sodium Coolant," Nucl. Eng. Design 30, 434-443 (1974). 
76. C. E. Ashbaugh, III, "Liquid Sodium-Reactor Fuel Interaction," Masters Thesis, Univ. of California, Los Angeles (1972).

77. J. B. van Erp et al., "An Evaluation of Pin-toPin Failure Propagation in LMFBR Fuel Subassemblies," in Proc. Fast Reactor Safety Meeting, Beverly Hills, California, April 2-4, 1974, U.S. Atomic Energy Commission report CONF. 740401-P2, pp. 615-640 (1974).
78. W. W. Marr et al., 'Subassembly to Subassembly Failure Propagation: Thermol Loading on Adjacent Subassembly," in Proc. Fast Reactor Safety Meeting, Beverly Hills, California, April 2.4, 1974, U.S. Atomic Energy Commission report CONF-740401-P2, pp. 598-614 (1974). 